\title{
Additionality or crowding-out? An overall evaluation of public $R \& D$ subsidy on private $R \& D$ expenditure
}

Citation for published version (APA):

Marino, M., Lhuillery, S., Parrotta, P., \& Sala, D. (2016). Additionality or crowding-out? An overall evaluation of public R\&D subsidy on private R\&D expenditure. Research Policy, 45(9), 1715-1730. https://doi.org/10.1016/j.respol.2016.04.009

Document status and date:

Published: 01/11/2016

DOI:

10.1016/j.respol.2016.04.009

Document Version:

Accepted author manuscript (Peer reviewed / editorial board version)

Document license:

CC BY-NC-ND

\section{Please check the document version of this publication:}

- A submitted manuscript is the version of the article upon submission and before peer-review. There can be important differences between the submitted version and the official published version of record.

People interested in the research are advised to contact the author for the final version of the publication, or visit the DOI to the publisher's website.

- The final author version and the galley proof are versions of the publication after peer review.

- The final published version features the final layout of the paper including the volume, issue and page numbers.

Link to publication

\footnotetext{
General rights rights.

- You may freely distribute the URL identifying the publication in the public portal. please follow below link for the End User Agreement:

www.umlib.nl/taverne-license

Take down policy

If you believe that this document breaches copyright please contact us at:

repository@maastrichtuniversity.nl

providing details and we will investigate your claim.
}

Copyright and moral rights for the publications made accessible in the public portal are retained by the authors and/or other copyright owners and it is a condition of accessing publications that users recognise and abide by the legal requirements associated with these

- Users may download and print one copy of any publication from the public portal for the purpose of private study or research.

- You may not further distribute the material or use it for any profit-making activity or commercial gain

If the publication is distributed under the terms of Article $25 \mathrm{fa}$ of the Dutch Copyright Act, indicated by the "Taverne" license above, 
This work is licensed under the Creative Commons Attribution-NonCommercial-NoDerivatives 4.0

International License. To view a copy of this license, visit http://creativecommons.org/licenses/by-nc-nd/4.0/

\title{
Additionality or crowding-out? An overall evaluation of public
}

\section{R\&D subsidy on private $R \& D$ expenditure.}

\author{
Marianna Marino * $\quad$ Stephane Lhuillery ${ }^{\dagger} \quad$ Pierpaolo Parrotta $^{\ddagger} \quad$ Davide Sala $^{\S}$
}

\begin{abstract}
This study analyzes the effect of public R\&D subsidies on private R\&D expenditure in a sample of French firms during the period 1993-2009. We evaluate whether there is any input additionality of public R\&D subsidies by distinguishing between R\&D tax credit recipient and non-recipient firms. In addition, combining difference-in-differences with propensity score and exact (both simple and categorical) matching methods, we assess the effect of R\&D subsidies between treated (subsidy recipients) and controls (subsidy non-recipients) as well as between differently treated (small, medium and large subsidy recipient) firms. Furthermore, we implement a dose-response matching approach to determine the optimality of public R\&D subsidy provisions. We find evidence of either no additionality or substitution effects between public and private R\&D expenditure. Crowding-out effects appear to be more pronounced for mediumhigh levels of public subsidies, and generally under the R\&D tax credit regime. A number of robustness checks corroborate our main findings.
\end{abstract}

JEL Classification: C14, H50, 038.

Keywords: R\&D subsidy; R\&D tax credit, optimal provision of public R\&D support.

* Corresponding author, ICN Business School, Department of Strategy and Entrepreneurship, 3 Place Edouard Branly, 50070 Metz Technopole, France; and Bureau d'Économie Théorique et Appliquée (BETA), UMR CNRS 7522, Université de Lorraine, France. E-mail: marianna.marino@icn-groupe.fr

${ }^{\dagger}$ ICN Business School, Department of Strategy and Entrepreneurship, 3 Place Edouard Branly, 50070 Metz Technopole, France; and Bureau d'Économie Théorique et Appliquée (BETA), UMR CNRS 7522, Université de Lorraine, France. E-mail: stephane.lhullery@icn-groupe.fr

${ }^{\ddagger} I C N$ Business School, Department of Human Resource Management and Organizational Behavior, 13 Rue Michel Ney, 54000 Nancy, France; Bureau d'Économie Théorique et Appliquée (BETA), UMR CNRS 7522, Université de Lorraine, France; Maastricht University, School of Business and Economics, Department of Economics, Tongersestraat 53, 6200 MD Maastricht, Netherlands; and Aarhus University, Tuborg Research Centre for Globalization and Firms, Fuglesangs Allé 4, 8210 Aarhus V., Denmark. E-mail: pierpaolo.parrotta@icn-groupe.fr

$\S$ University of Passau, Faculty of Business Administration and Economics, Chair of International Economics, Dr.-HansKapfinger-Str. 14b, 94032 Passau, Germany; and Aarhus University, Tuborg Research Centre for Globalization and Firms, Fuglesangs Allé 4,8210 Aarhus V., Denmark. E-mail: davide.sala@uni-passau.de. 


\section{Introduction}

Public support to private R\&D investments is theoretically grounded in market failures associated with the incomplete appropriation of the returns to $\mathrm{R} \& \mathrm{D}$ investments. The role of public policy is then to remedy to this negative externality and propel private $R \& D$ investments to an optimal social level. The justification of public intervention has gained further momentum in the recent macroeconomic literature, which accounts for a far richer interplay of externalities characterizing R\&D activities (Temple, 2003; Montmartin and Massard, 2015) 11 Whereas the macroeconomic approach evaluates the effectiveness of policies at the sectoral or country level, allowing also for spatial spillovers (Montmartin and Herrera, 2015), the rich microeconomic empirical literature - which our study contributes to - focuses on the role of a specific measure of financial support to $R \& D$ to increase firms' levels of $R \& D$ investments. This role could not be more apparent than in the recent economic crisis. As noted by the OECD (2013), many governments have adopted a number of measures aimed at supporting firms' innovation. These measures reflect the conviction of policy makers that an adequate level of innovation is not only crucial to business success, but it is also a decisive factor to recover from the downturn ${ }^{2}$ However - even if governments allocate public resources in favor of those projects that would not have been realized in the absence of public support (crowding-in or additionality) ${ }^{3}$ it is plausible that eligible firms simply substitute R\&D investments they originally planned to undertake with the public financial resources made available (crowding-out), undermining the argument for "additional" effects of public aid. To strike a balance between "crowding-in" and "crowding-out" effects that typically plague such public policies, policy makers are assigned the tasks of designing (i) the eligibility criteria allowing firms to benefit from a public R\&D grant, (ii) the modulation of public intervention, and (iii) the optimal policy mix to achieve defined technology policy objectives.

Considerable volumes of resources are spent each year in R\&D public funding, and not surprisingly, the academic debate has focused on the analysis of those policies and, in particular, on the assessment of their effectiveness. Evaluating the extent of the economic payoff of a public grant to R\&D is basically an empirical question, but assessing its impact is a challenging task. The main problems are due to the difficulties faced $a$ ) in controlling for selection bias, $b$ ) in discriminating the potential different effects induced by heterogeneous treatment levels provided to firms through the $\mathrm{R} \& \mathrm{D}$ public subsidy, and $c$ ) in isolating the effects of the subsidies from the other confounding factors such as the contextual implementation of other R\&D policies.

Different from many existing studies, our empirical analysis aims at addressing these concerns. We argue that an overall assessment of public grant support to R\&D activities should evaluate not only the advisability

\footnotetext{
${ }^{1}$ See also Reis and Sequeira (2007), Alvarez-Pelaez and Groth (2005).

${ }^{2}$ In line with this argument, Autio and Rannikko (2016) find that the impact of a Finnish high-growth entrepreneurship policy initiative (NIY programme) enhanced new firm growth, being robust against the post-2008 global financial crisis.

${ }^{3}$ For the use of this terminology - "crowding-in" - see Diamond (1999), p. 424.
} 
of public support but also its modulation as well as the presence of other unobserved contextual factors (among which the contextual presence of different R\&D policy tools is the most obvious), equally important aspects, yet under-studied in this literature ${ }^{4}$ Thus, to investigate the implications of the modulation of public R\&D subsidies along different dimensions, we divide recipient firms into a number of groups defined in terms of the percentile (tercile) of the public subsidy received. First, we simply consider how different (small, medium or large) amounts of R\&D grants impact the advisability of public R\&D. By comparing R\&D outcomes between similar funded and not funded firms or between similar but differently funded firms, we can establish which groups of recipients are primarily contributing to the growth of $R \& D$ investment in the economy. The outcome variables we look at are both the (log-) level and growth of private R\&D expenditure. Interestingly, the comparison of results in level and growth allows us to identify the potential bias due to the correlation between the firm-specific unobservable term and the treatment variable. As highlighted in solid and recent development of policy evaluation methods in empirical microeconomics (Blundell and Costa Dias, 2000; Blundell and Costa Dias, 2009) as well as in key contributions in the literature on the R\&D public funding (Aerts and Schmidt, 2008; Görg et al., 2008), the implementation of matching methods with outcome variables in first differences may remove any potential bias due to time-invariant firm-specific factors that the available data do not allow one to control for. Furthermore, and more importantly, matching firms on their pre-treatment characteristics in each observational year, we control for time-varying observables, which may well proxy time-varying unobservables that potentially affect the treatment and the outcome variables simultaneously. Employing a categorical treatment evaluation scheme, we compare publicly financed firms with similar characteristics across different groups. Our econometric exercise is implemented by combining both propensity score and exact matching techniques 5 Whereas the former is computed on all observables, the latter allows us to further strengthen the precision of the comparison by fixing an exact matching among a number of categories (e.g., firm size, industry, and past recipient status). The policy relevance of these comparisons is hard to question, as it is needed to determine whether firms benefiting from the largest amounts of public funding are also investing more in $\mathrm{R} \& \mathrm{D}$. If this is not the case, then public authorities may improve their policy targeting through funds re-allocation among recipients. Second, we turn to the question of determining the proper modulation of R\&D public financing. By means of the continuous (dose-response) treatment matching scheme $\sqrt[6]{6}$ we can evaluate the effect of further increasing the public grant on private R\&D expenditure, as this method can identify the marginal effects of subsidies and their optimal amounts. The amount at which the public support ceases to be beneficial can therefore be determined. Third, we

\footnotetext{
${ }^{4}$ See Blundell and Costa Dias (2000) and Aerts and Schmidt (2008).

${ }^{5}$ See Leuven and Sianesi (2014), and Abadie et al. (2004) for statistical packages performing propensity score and exact matching methods, respectively.

${ }^{6}$ See Bia and Mattei (2008).
} 
do not test the effects of the R\&D subsidy in isolation only, but we test the impact of the R\&D subsidy under the provision of tax credits to R\&D performers. Specifically, R\&D subsidy recipients are compared with non-recipients as well as with firms benefiting contextually from R\&D subsidies and R\&D tax credits. Finally, by taking advantage of an unusual characteristic of the R\&D national policy in France that created the conditions for a policy change, notable discontinuities in the average R\&D tax credit clearly emerged in 2004 and 2008, which were the years of major reshaping of this policy tool by the French authorities, we can strengthen the causal interpretation of our findings by incorporating considerations relative to the exploitation of exogenous variations in the public R\&D provision.

In our empirical analysis, we find evidence of significant substitution between private and public funds to R\&D, especially for medium-high levels of public subsidies. Crowding-out effects appear to be stronger under the R\&D tax credit regime. Comparing growth in private R\&D expenditure of companies with similar characteristics, we find that recipients of larger doses do not outperform or appear to perform worse than recipients of lower doses or non-recipient firms. In addition, firms employing fewer than 100 workers or operating in low-R\&D intensive industries typically report more extensive substitution compared with their counterpart samples. Examining the effects for specific amounts of subsidy provision, we find that fully supported firms receiving subsidies between EUR 145 thousand and 1.8 million seem to exhibit significant lower private contribution with respect to their counterfactual units, whereas additionality effects are found for few top beneficiary companies (above EUR 10 million). Different results are found for subsidy-only recipients, which show significant substitution for subsidy doses between EUR 20-55 thousand. Furthermore, the 2004 reform of R\&D tax credit incentives appears to have worsened the crowding-out behavior of firms benefiting from public R\&D subsidies under the new and more generous tax credit scheme. Although our findings present higher internal and external validity, due respectively to the strength of the deployed empirical methods and to the focus on a big European country such as France, a limitation of this study may be related to the coverage of our firm population dataset. Indeed, we do not observe companies with fewer than 20 employees in the manufacturing industries, which represent a relevant proportion of French small and medium size enterprises.

The remainder of this paper is structured as follows: section 2 briefly reports the literature and institutional background, section 3 describes the main econometric techniques we employ, section 4 summarizes the data and variables, section 5 reports our main findings and robustness checks, and section 6 offers concluding remarks. 


\section{Additionality, hidden treatments and policy changes}

The empirical literature concerned with the evaluation of $R \& D$ policies has typically relied on the notion of additionality as an indicator of policy effectiveness. The concept of "additionality" was introduced by Buisseret et al. (1995) and indicates the difference made by the state interference in the market. The argument can be summarized as follows: economic theory and empirical findings robustly support the positive relationship linking R\&D investment and economic growth. Then, assuming that public aid for technological developments induces private firms to undertake "additional" R\&D investments (i.e., firms that would have not undertaken those $R \& D$ investments without public support), it is possible to infer that the policy intervention leads to economic growth and social welfare. To address the inquiry of "additionality," evaluations of public financing programs typically present casual analyses based on counterfactuals, what would have occurred in the absence of intervention. At the heart of this analysis is the recognition that neither firms that have received support nor firms that have not applied for funds can be considered random events. On the contrary, firms' behavior is the explicit consequence of the policy design, as firms are often aware of those criteria on the basis of which governmental authorities will decide funds allocation (i.e., self-selection). In this respect, our study is no exception and follows this strand of literature, assessing the French R\&D grant support system performing an "after the fact" analysis as in Almus and Czarnitzki (2003), Blanes and Busom (2004), Czarnitzki and Licht (2006), and González and Pazó (2008), Hussinger (2008), among others.

It is undeniable that a plethora of studies implementing different approaches and overcoming database limitations in different ways has generated a vast mix of evidence, ranging from being in favor of "crowding-in" effects (Görg et al., 2008; Aerts and Schmidt, 2008; Hussinger, 2008) to being unable to reject "crowding-out" effects (Lach, 2002; Heijs and Herrera, 2004) 7 In a recent meta-regression analysis, Dimos and Pugh (2016) find no evidence of either crowding-out or substantial additionality effects, and state that the treatment of unobservable firm heterogeneity plays a key role in explaining the heterogeneous effects reported in this literature.

Our study partly relates to Görg et al. (2008), Hottenrott et al. (2014) and Guerzoni and Raiteri (2015). Görg et al. (2008) find that additionality in R\&D subsidies holds for small grants, whereas large grants seem to induce crowding-out. They implement the categorical matching but neglect - one of our salient contributions - the continuous treatment approach in evaluating the effects of R\&D promoting policies. Furthermore, content-wise, the outcome we consider, the private $R \& D$ expenditure, is different from the outcome they focus on, the engagement of firms in international markets.

\footnotetext{
${ }^{7}$ See also Aerts and Czarnitzki (2004, 2006), Almus and Czarnitzki (2003), Busom (2000), Czarnitzki and Fier (2001), David et al. (2000), Duguet (2004), Garcia-Quevedo (2004), Gonzalez et. al (2005), Gonzalez and Pazo (2008), Lööf and Heshmati (2005), Suetens (2002), and Wallsten (2000).
} 
Employing a continuous treatment (dose-response) matching approach and exploiting a specific policy design that explicitly distinguishes between research and development grants, Hottenrott et al. (2014) estimate direct and cross-scheme effects on research versus development intensities in a sample of recipients firms. However, this study neglects the potential existence of crowding-out, in terms of both research and development, or one of the two, emerging from the comparison with non-funded firms.

Guerzoni and Raiteri (2015) argue that the framework created by the matching methodologies can suffer from serious limitations due to unobserved variables that can act as potential confounding factors in the analysis. In particular, their focus concerns the role played by other R\&D policies that if remain unobserved can act as "hidden treatments" on the outcome variable and lead to biased estimations. To cope with this issue, they employ only a standard matching technique in which three R\&D policy instruments (i.e., R\&D subsidy, innovative public procurement and $R \& D$ tax credit) are considered as treatment variables and evaluated first in isolation and then in combination with each other. As a consequence, Guerzoni and Raiteri (2015) neither inform on the effects arising from the comparison between differently treated groups of recipient firms nor provide evidence on the optimal treatment dose of each $R \& D$ policy instrument in isolation or combination with the others.

In addition, all three mentioned studies do not fully address bias associated with either time invariant or time varying firm-specific effects. We address both sources of unobserved heterogeneity by employing a DID in combination with matching technique approaches. Specifically, taking the first differences in our outcome variable, we remove the time invariant unobserved component, and performing a matching between treated and controls in each observational year (which is the frequency of our panel data), we make sure that comparisons include all observable within-firm changes occurring on an annual basis, which are likely to be correlated with varying unobservables. Furthermore, comparing DID estimates between two consecutive years, we can identify causal effects of policy changes introduced by public authorities.

Indeed, the French public R\&D funding system is particularly apt for the empirical evaluation proposed in this study. France is among the European countries with the highest budget devoted to the distribution of public R\&D financing toward private companies. Public authorities have been implementing both direct and indirect $R \& D$ policy instruments for business R\&D. Since the early 1990s, the French government has introduced several reforms, whose goal has been the creation of a proper framework for boosting innovation. R\&D public resources have been distributed on the basis of predetermined criteria such as the level of risk and innovativeness of the proposed projects, the promotion of university-firm collaborations, and the support of new high-tech firm formation, especially when associated with young innovative entrepreneurial projects. Moreover, to reach the target of R\&D spending (at least 3\% of GDP) of the Lisbon strategy, since 2004, a substantial portion of public funding (with annual average investments of EUR 450 million) has targeted the 
"Pôles de compétitivité", which consist of dynamic and competitive clusters of France, often focused on the investments in advanced technological areas such as biotechnology and nanotechnology. This policy change made available $\mathrm{R} \& \mathrm{D}$ grants for projects designed to boost collaborative $\mathrm{R} \& \mathrm{D}$ networks (favoring technological transfers as well as other entities such as Public Research Organizations).

The year 2004 has been characterized by a further and most likely more impressive reform of the French public $R \& D$ funding system, related to the $R \& D$ tax credit. Until 2004, the French tax credit was an incremental tax credit scheme set at the $50 \%$ rate and defined as follows: $\left[0.5 *\left(R \& D_{t}-R \& D_{t-1}\right)\right]$. In 2004 this policy tool has been re-defined as a combination of level and incremental tax credit: $\left[0.65 *\left(R \& D_{t}\right)+\right.$ $\left.0.45 *\left(R \& D_{t-1}-R \& D_{t-2}\right)\right] \mathrm{g}^{8}$ in the spirit of the $\mathrm{R} \& \mathrm{D}$ tax credit adopted in other countries such as Japan, South Korea, Portugal and Spain. The ceiling of approximately EUR 0.5 million in 1983 reached EUR 8 million in 2004 and EUR 16 million in 2007.

Due to the 2007-2009 financial and economic crisis, the GDP decline has often been followed by a substantial drop in long-term investments in innovation (Filipetti and Archibugi, 2011; Archibugi et al., 2013) and a rising fear of industrial $\mathrm{R} \& \mathrm{D}$ delocalization. France, as have many countries, considered public $\mathrm{R} \& \mathrm{D}$ spending as a strategic policy to counteract the effects of the recent economic downturn, in spite of budgetary pressures due to the rising deficit and debt 9 Specifically, in 2008, the French government decided to eliminate the existing ceiling and the incremental component of the R\&D tax credit with the objective of pushing firms to invest more resources in $\mathrm{R} \& \mathrm{D}$ activities. This transformed the French $\mathrm{R} \& \mathrm{D}$ tax credit into the most generous scheme among OECD countries (OECD, 2009).

\section{Methodology}

This section briefly discusses the estimation strategies implemented in our empirical assessment of public R\&D subsidies in the absence or combination of tax credit policies. Taking advantage of recent advancements in program evaluation analysis, we have combined the categorical (both pscore and exact version) and continuous (dose-response) treatment matching schemes. The inclination to reduce biases arising from non-random assignments makes these methods widely utilized in the field of causal inference in observational studies. To provide some insight into the methodology as well as to discuss the strengths and the weaknesses of each method, we discuss them separately.

\footnotetext{
${ }^{8}$ The balance between the level and the incremental components was subsequently modified in 2006 with $10 \%$ and $40 \%$ rates, respectively. Further changes have also been introduced since 2008: the regular $30 \%$ rate has been applied up to EUR 100 million and dropped to $5 \%$ beyond this threshold. However, firms applying for the first time could benefit from a $50 \%$ rate in the first year and a $40 \%$ in the second year.

${ }^{9}$ Academic articles on this matter empirically show that government transfers and subsidies became substantially more countercyclical (Galí, 1994), and increasing public investments in R\&D were invoked. The crucial role of R\&D public financing was therefore justified not only in light of the cited market failure argument but also because of the pro-cyclical character of private $\mathrm{R} \& \mathrm{D}$ investments.
} 


\subsection{Categorical Treatment Matching}

It is tautological that the final $R \& D$ spending will depend on the amount of the public support received by a firm. However, coupling the information on the $\mathrm{R} \& \mathrm{D}$ support receipt by a firm with the information on the amount received opens the prospective of an analysis based on the categorical treatment matching. The categorical (propensity score and exact) matching evaluates the expected class of treatment a firm may receive given the pre-treatment variables. Consistent with the rationale of the dichotomous matching, the estimation of the public intervention impact is based on the comparison of firms with similar scores (and given some exactly similar pre-treatment characteristics in the exact matching), but belonging to two different classes or categories. In our study, these categories are defined by looking at the terciles of the distribution of public R\&D funding (i.e., small, medium, and large categories). It surely represents an objective rule, and therefore, it is not subject to being fully arbitrary and potentially misleading categorization criteria. In fact, we face the trade-off between the number of groups analyzed with the observations available in each group. If the number of observations is not sufficient, not only estimates lose efficiency, but the estimation method also becomes unfeasible due to the lack of a common support. This limit may not affect the continuous matching method because it approximates the distribution of public funds according to a normal density function.

The categorical matching estimation method is well suited for comparisons not only between two categories of treated groups but also between treated and untreated (which is not allowed in the continuous treatment case) groups. It helps a lot in understanding whether a given effect obtained from the single-treatment framework is simply driven by a single category of treated or it is concretely confirmed for all categories, i.e., the homogeneity of treatment in the last case may represent a more plausible and acceptable assumption than in the simple dichotomous matching.

Thus, we have the outcome $\left\{Y^{0}, Y^{1}, Y^{2}, Y^{3}\right\}$ of 4 different mutually exclusive treatment categories, where the 0 - category is exclusively composed of untreated, the 1-,2-, and 3 -category are the small, medium, and large subsidy recipient categories. Obviously, we can observe only a realization of the potential outcome vector; the remaining ones are counterfactuals. To estimate the different treatment effects, the unconfoundedness and common support assumptions must be satisfied. Given the covariates, whereas the unconfoundedness requires the treatment indicator to be independent of the realized outcomes, the common support ensures finding a counterpart in the comparison group, which is addressed by the computation of the propensity score. In this regard, a practical suggestion is that the existence of differently treated units can be ignored in a given pairwise category comparison because they are not needed for identification purposes.

For the implementation of the categorical matching, we must run as many probit estimations as the number of effects we are interested in. Therefore, once identified the probability of receiving a given subsidy 
size compared with another one (e.g., small vs. medium), conditional on the set of pre-treatment covariates, it is possible to compute the associated treatment effect. Counterfactuals are selected by utilizing the caliper method (set at 0.01), which represents a scalar defining the boundary of the neighborhood in which matching is allowed. In this way, we seek to ensure the quality of matching because 'bad' matches are prevented from being included in the comparison groups.

\subsection{Continuous Treatment Matching}

The implementation of the continuous treatment matching allows us to compare enterprises exposed to a specific level of treatment with 'matched' less and more exposed ones and then to identify marginal effects on firms' private R\&D investment. The treatment group is alternatively composed of firms receiving public $R \& D$ funding only or those benefiting from both $R \& D$ subsidies and $R \& D$ tax credits. The control group is defined as the set of firms receiving lower doses of $R \& D$ subsidy (with or without $R \& D$ tax credit).

The continuous treatment approach becomes particularly helpful when the number of treatment values is relatively large because as noted by Imbens and Wooldridge (2009), the possibility of smoothing across treatment permits the improvement of the precision of the inference. This estimation strategy is based on the key assumption, weak unconfoundedness, formulated by Imbens (2000), which requires only the pairwise independence of the treatment with each (not joint) of the potential outcomes. In this way, it overcomes one of the limitations of the so-called conditional independence assumption (CIA) made by Rosenbaum and Rubin (1983) for the binary case. Thus, the problems of bias removal and drawing causal inferences can be solved by adjusting for pre-treatment differences. Based on pre-treatment variables, it is possible to compute the conditional probability of receiving a specific level of treatment (not just receiving it), which takes the

name of General Propensity Score (GPS). An important property originates from the fact that the weak unconfoundedness given all pre-treatment characteristics implies weak unconfoundedness given the GPS, so the average treatment effects can be obtained by conditioning just on the GPS (Hirano and Imbens, 2004). More details on the key assumptions and implementation of the continuous matching method are provided in Bia and Mattei (2008).

\section{Data, variables and descriptive statistics}

\subsection{Data}

We combine six different data sources on individual firms to build our final dataset. Our first data source is composed of $R \& D$ data for the period 1993-2009 from the mandatory survey on R\&D (Statistics Office - 
Ministry of Higher Education and Research) collected each year by the Direction of Evaluation, Prospective and Performance (DEPP). This so-called "R\&D survey" inquires into the amount and the types of investments and expenditures related to R\&D as defined in the Frascati Manual guidelines (OECD, 2002). It includes declarative data such as the amount of internal and external $R \& D$ investments as well as the different external funding coming either from public bodies or private firms. Public R\&D funding includes civil and military R\&D contracts as well as R\&D subsidies granted by the different public administrative bodies in charge of R\&D policies (e.g., Ministry of Research and Ministry of Industry) or other public agencies (e.g., Oséo-ANVAR, ADEME).

Our second data source is the R\&D tax credit register from the Ministry of Higher Education and Research, which manages the French R\&D tax scheme. The data are exhaustive and reveal the amount of R\&D tax credit obtained by firms on a yearly basis. As a negative tax credit can be carried forward by firms, the net positive value of the annual tax credit is considered the amount likely to positively affect the efforts of firms in R\&D investments. Furthermore, since 1997, firms should have consolidated their R\&D declarations and $R \& D$ tax credit claims at the business group level. The R\&D tax credit files allow us to identify fiscal groups: the headquarters as well as the subsidiaries they are consolidated with.

The third dataset is the annual business survey EAE (enquêtes annuelles d'entreprises) from 1993 to 2007. The survey managed by the French National Institute of Statistics and Economic Studies (INSEE) reports the individual characteristics of French manufacturing firms with more than 20 employees and service firms with more than 10 employees. It provides the main activity (NACE code), accounting data, and some data on the workforce and investments. Among them, the number of employees, value added, exports, cash flow and operating subsidies are variables of particular interest to us. Our fourth dataset, ESANE (Elaboration des statistiques annuelles d'entreprise), was provided by the Ministry of Finance for 2008 and 2009 in place of the annual business survey, which, however, is no longer available. ESANE consists of different fiscal and administrative data coming from fiscal and social declarations. The file is not a survey and encompasses millions of firms compared to the EAE files. Most of the variables originating from the EAE survey can be retrieved in ESANE. Missing values are, however, more frequent, especially for SMEs. We thus complete the ESANE data with our fifth source of information: a private database (DIANE) gathering the information disclosed to commercial courts by French firms and published by Bureau van Dijk. When data from ESANE are missing, we impute them by utilizing DIANE values.

Our sixth data source is the 'financial linkages' dataset (LIFI) that covers the period 1993-2009 and is provided by INSEE in collaboration with Bureau van Dijk. LIFI provides information about the headquarters for every subsidiary that is located in France and that is fully owned (at least at 50\%) by another firm. Thanks to LIFI, we are able to identify firms located in France owned by foreign companies. 


\subsection{Variables}

Obviously, the treatment variable is the amount of the $R \& D$ subsidy received from the government or other public institutions.

Our matching techniques are based on the following pre-treatment variables: R\&D intensity indicator (private $\mathrm{R} \& \mathrm{D}$ expenditure over value added), dummies indicating the decile (from the second to the tenth) associated with the private R\&D expenditure, dummies for positive cash flow, exports scaled to sales, foreign ownership, dummies referring to the second and third distribution terciles of our treatment variables and other subsidy, 2-digit industry and size dummies. Specifically, size dummies are defined as follows: firms between 20 and 49, between 50 and 99, 100 and 499 and equal to or larger than 500 employees. This classification finds justification in the French industrial structure that is dominated by SMEs: enterprises with less than 50 employees account for more than $95 \%$ of the total firm population (e.g., Garicano et al., 2013).

Several among these covariates typically also appear in the related literature. The size and industry dummies account for potential common demand/supply shocks or idiosyncratic shocks to a given company size or a given industry level, while the other pre-treatment variables capture unobservable or observable firm heterogeneity. The inclusion in the selection equations of the dummies indicating past public support accounts for firms' 'dependence' on public resources. The inclusion of both the past R\&D intensity indicator and the deciles of past private R\&D expenditure significantly improves the comparability of treated and controls or differently treated firms when we use private $R \& D$ growth as an outcome variable. Indeed, the inclusion of such pre-treatment characteristics may ensure that the additionality concept, arising from the comparison of the outcome variables in first differences, is not biased in favor of low-R\&D performers. The cash flow dummy serves as a proxy for firm financial constraints: if the policy maker prefers to support businesses with financial constraints, firms with a positive cash flow may result in a disadvantaged position vis-a-vis firms with negative cash flows. The exports sales ratio and the variable indicating the foreign ownership may reveal a policy maker's inclination to fund companies more active in international markets, possibly characterized by higher productivity levels with larger potential for innovations ${ }^{10}$ Thus, each variable in the selection equation expresses our attempt to account for all possible criteria that French public authorities may use for the targeting of their subsidies.

\subsection{Descriptive statistics}

Figure 1 presents the average annual public R\&D subsidy and $R \& D$ tax credit for all observed firms. Consistent with what was stated in the section on the institutional background, we observe an increasing amount

\footnotetext{
${ }^{10}$ Bernard and Jensen (1999) and Melitz (2003), among others.
} 
of public resources devoted to the $R \& D$ tax credit and a trend reduction in the provision of $R \& D$ subsidies over time. A notable discontinuity in the average R\&D tax credit clearly emerged in 2004 and 2008, which were the years of major reshapings of such a policy tool. Figure 2 adds further information on the level of average private expenditure in R\&D. In our sample, it increases from the early 1990s to the year 2000 and decreases afterwards. In Figure 3, the average private R\&D expenditure for both treated (with subsidy only) and untreated and the average total public $\mathrm{R} \& \mathrm{D}$ financing to recipients are reported. It emerges that on average financed firms invest more in their research activities.

Figure 1, 2 and 3 about here

The following descriptive statistics and results refer to our final sample, which consists of firms reporting positive $R \& D$ expenditure both in the current and previous year. Table 1 describes the main variables employed in the analysis, favoring the comparisons across three categories of firms. The first two variables listed are the treatment variables: $R \& D$ public subsidy and total $R \& D$ tax credit. Next, the outcome variables are the (log-) level of private $\mathrm{R} \& \mathrm{D}$ and growth of private $\mathrm{R} \& \mathrm{D}$. The remaining listed variables are the covariates utilized to determine the matching between control and treated. Firms are divided into three groups: $R \& D$ subsidy recipients, $R \& D$ subsidy and $R \& D$ tax credit recipients and non-recipients. The control group includes 7,556 companies, whereas the treated groups consist of 2,535 enterprises funded with $\mathrm{R} \& \mathrm{D}$ subsidies and 2,078 firms supported with both $\mathrm{R} \& \mathrm{D}$ subsidies and $\mathrm{R} \& \mathrm{D}$ tax credits. Although most of the pre-treatment variables are relatively similar when we compare R\&D subsidy recipients with $R \& D$ subsidy and $R \& D$ tax credit recipients, it is worth noting that the $R \& D$ intensity is much higher for enterprises financed with both policy tools, whereas firms receiving solely $R \& D$ subsidies report an $R \& D$ value added ratio just slightly higher than non-funded firms. In addition, current recipient firms have more likely benefited from public support schemes in the previous periods. Comparing average outcome variables among firm groups, we observe that the highest level of private $R \& D$ expenditure is associated with recipients of both $R \& D$ subsidy and $R \& D$ tax credit, followed by subsidy-only recipients and by non-recipients. However, this ranking changes drastically if we consider the average growth of private $R \& D$ expenditure: non-recipients appear to outperform fully supported firms, and subsidy-only recipients perform better than non-recipient firms.

Table 1 about here

Table 2 and Table 3 present a similar structure as the previous table and facilitate the comparisons between different groups of firms: funded firms are divided into three groups corresponding to the first, second and third tercile of the public subsidy distribution. It turns out that companies receiving larger amounts of public 
R\&D subsidy are more likely to be (a) large and domestic firms, (b) concentrated in high-tech industries 11 (c) former large recipients of both $R \& D$ subsidy and $R \& D$ tax credit, and of other public subsidies. However, it is worth underlining that large $R \& D$ subsidy recipients present the lowest $R \& D$ value added ratio among the companies that do not benefit from R\&D tax credit support. More interestingly, Tables 2 and 3 show that whereas the average private $R \& D$ expenditure increases with the tercile of public $R \& D$ provision, a similar pattern does not emerge when considering the growth of private $R \& D$ expenditure as the outcome variable. This, combined with the similar statistics reported in Table 1, represents interesting prima facie evidence that if confirmed in our causal analysis, may cast serious concerns on the targeting and effectiveness of public resources devoted to propel private $R \& D$ expenditure.

Table 2 and 3 about here

\section{Results}

This section presents results based on our categorical and continuous matching evaluation schemes. In the first approach, we divide financed firms into three categories reflecting the terciles of the distribution of the R\&D support grant as well as the terciles of the distribution of the R\&D subsidies under R\&D tax credits. This choice is clearly data-driven because it is not grounded on any a priori knowledge about optimal amount thresholds. Although the decision of partitioning the entire distribution of our treatment variables in three almost equally populated groups is to some extent arbitrary, it appears to us as the most sensible option given the size of our sample.

Tables 4 and 5 summarize the estimates obtained by means of the categorical matching method for our outcome variables, namely the log-level and the log-difference (i.e., growth) in private R\&D spending. Whereas the former variable eases the interpretation of our treatment effect, the latter better accounts for time-invariant unobserved heterogeneity and therefore constitutes our benchmark when evaluating the average treatment on treated (ATT) estimates.

The first three columns of Table 4 are related to the R\&D subsidy only. The first column refers to the standard dichotomous matching method in which all categories of publicly financed firms (small, medium and large R\&D subsidy-only recipients) are compared with untreated ones (non-recipients). This simple comparison exhibits a quite large positive and significant effect of public subsidy provision: on average, the set of financed firms invests approximately 39\% more than non-financed ones. However, scrutinizing the pairs of differently funded versus unfunded companies, this result is not confirmed for the first and for the second terciles. In these cases, the treatment effect is either negative or positive but insignificant. Whereas

\footnotetext{
${ }^{11}$ This does not emerge from Tables 2 and 3 but is reported in Table 6.
} 
small grant and medium grant recipient firms do not outperform untreated ones, large grant recipients invest significantly more in private $R \& D$ than non recipients. This underlines the importance of splitting the treatment evaluation in our three categories. Interestingly, the input additionality emerges extensively in all other comparisons between more and less treated firms (columns 2 and 3). More precisely, medium grant recipients spend on average approximately $19 \%$ more than small ones, and large grant recipients invest approximately $82 \%$ and $61 \%$ more than small and medium grant recipients, respectively. These findings are in line with the effects of the public $R \& D$ subsidy provision in combination with the $R \& D$ tax credit support, which are shown in the last three columns of Table 4. Significant additionality effects emerge when comparing large grant recipients with less supported firm groups or non recipient companies, but medium grant recipients do not outperform small grant recipients.

Table 4 about here

However, opposite (mostly negative and significant) results are reported in Table 5, where ATTs are differences in private $R \& D$ growth between firm groups. Indeed, we find notable crowding-out evidence in almost all pair-wise comparisons for both types of treatments, ATTs ranges from -0.09 (-0.14) to -0.23 (0.26) in the sample of subsidy (subsidy under tax credit) recipients. Although negative, insignificant effects are found when (i) comparing small grant recipients with non-recipients, and (ii) confronting large R\&D grant recipients with medium ones. This clearly indicates that the bias due to the correlation between the firm-specific time-invariant unobservable term and the treatment variable is positive and higher for firms receiving larger amounts of subsidies. Because differences in $\mathrm{R} \& \mathrm{D}$ growth account better for firm specific time-invariant effects, we are more confident in evaluations having such an outcome variable, and henceforth we report and discuss solely results in first differences. Thus, it appears that recipient companies may substitute private $R \& D$ expenditure with public $R \& D$ subsidies. In line with this argument, we deepen our analysis to investigate the role that different amounts of public R\&D subsidies may have in determining an additionality or crowding-out effect of public R\&D financing by performing a propensity score matching by year.

Table 5 about here

To this purpose, findings on the effectiveness of $R \& D$ public subsidies in the absence of or combination with $R \& D$ tax credits are respectively illustrated in Figures 4-15. In these figures, we plot the average growth of the private $R \& D$ expenditure for treated and controls, so vertical differences represent the treatment effects (ATTs). The presence of dots reveals that the computed ATT for a given year is statistically significant (at least) at the $10 \%$ level. The use of such graphs facilitates the comparison of ATTs over time and allows 
for an evaluation of the effects induced by sharp changes (discontinuities) in the provision of R\&D public support, i.e., first difference in ATT. However, if, on the one hand, the assignment of propensity scores by year improves the adequacy of matched pairs, on the other hand, a more demanding method reduces the number of matched firms and therefore, enlarges the estimated standard errors.

Figures 4-9 about here

Looking at the Figures 4-9, we find that in a few cases treated firms perform better than untreated ones (medium recipients in 2000, and large recipients 1995) and however no later than the 2004 reform. Moreover, proceeding with our inter-tercile comparisons, the figures display no significant higher R\&D growth of more treated compared with less treated groups over the sample period. The overall picture appears not to change much after the analysis of figures reporting the impact of subsidies under tax credits (Figures 10-15). Small and medium subsidy recipients under tax credits do not typically perform better than firms not receiving any R\&D public aid, the only additionality effect is found for small subsidy recipients in 1996. Compared with R\&D subsidy-only recipient subset, it turns out that crowding-out behavior occurs more often among fully supported companies for the inter-tercile comparisons.

Figures 10-15 about here

In addition to this set of results, we perform all comparisons previously described in the propensity score categorical matching analysis by employing the exact matching evaluation approach. The main difference between these two methods is that in the latter version, we impose an exact matching among a number of pre-treatment covariates: size, industry, (R\&D tax credit, $R \& D$ subsidy and other subsidy) recipient status, private R\&D deciles dummies, exporter status, and foreign ownership dummies. We report in Figures A1-A6 (A7-A12) the effects of $R \& D$ subsidies in the absence of (combination with) $R \& D$ tax credit. These graphs report ATTs (differences in average R\&D growth between treated and controls) by year. Overall, the exact matching findings are in line with the propensity score findings, confirming in particular the crowding-out effects in the after-reform period.

As stated above, we complement these results from the inter-tercile (i.e., categorical treatment) evaluation with those from the intra-tercile (i.e., continuous treatment) comparisons to add further information aimed at the overall assessment of the R\&D policy. As mentioned in the methodological section, the continuous treatment matching method allows for the comparison of responses given small increases in the treatment doses. It implies that non-recipients are not included in such an evaluation because their dose is zero (they are untreated). Figures 16-21, which refer to this method, report the treatment effect function on the y-axis and the treatment dose on the x-axis. Obviously, the treatment effect function informs on whether a small (about EUR 1,000) increase in the dose leads to a reduction or rise in the growth of private R\&D expenditure. 
Examining Figures 16-17 (or Table B1), we find evidence of crowding-out or no significant effects of public R\&D provision for doses below EUR 10 million, and additionality effects for doses above such an amount. It turns out that significant substitution of private with public R\&D resources is more likely among small and medium categories (between EUR 20,000 and 55,000) for the subsidy-only recipients, and among medium and large (between EUR 145,000 and 1,800,000) categories for fully supported companies. For instance, the provision of a further EUR 1,000 to fully supported recipients of EUR 1.8 million will reduce their growth of private $\mathrm{R} \& \mathrm{D}$ by approximately $0.3 \%$ compared to similarly treated firms that are not benefiting from such a dose increase. Crowding-out seems to be more pronounced for the $\mathrm{R} \& \mathrm{D}$ tax credit recipients.

Exploiting the exogenous variation due to the sharp change in $R \& D$ tax credit policy that occurred in 2004, we compare treatment effects on growth of R\&D private expenditure between before- and after-reform periods (see Figures 18-19 and 20-21, or Tables B2 and B3, respectively). We find mostly insignificant effects in the before-reform period, whereas companies benefiting of both schemes of public R\&D support show significant negative effects for doses falling between EUR 145 thousand and 1,8 million in the after-reform period. Interestingly, it appears that larger crowding-out effects for subsidy recipients under tax credits in the after-reform period, compared to either before-reform and full sample period.

Figures 16-21 about here

Finally, because there exist differences in the average additionality effects across industries or between firm size thresholds, as shown, for instance, in Castellacci and Lie (2015) and Guellec (2003), we perform a number of robustness checks (Table 6) to test whether our findings may (i) vary between small and large companies, or (ii) differ between high- and low-intensity R\&D industries, or (iii) depend on the amount of funding targeted towards defence activities. In all robustness checks, non-financed firms seem to outperform large subsidy recipients. It turns out that negative treatment effects appear stronger for "small firms" and companies operating in "low-R\&D" industries. When excluding the public R\&D financing towards defence projects, our findings are qualitatively in line with the main results and the other checks. Although robustness checks show that there exists a certain heterogeneity in the ATTs among subsamples, we still find evidence of either no additionality or substitution for both treatments under analysis.

Table 6 about here

\section{Discussion and Conclusions}

This paper is an overall evaluation of the public subsidies to $R \& D$, which proposes an assessment of this policy in absence or combination with the R\&D tax credit, an equally important policy instrument used 
to stimulate private R\&D investments. Using a dataset of French companies that covers the period 19932009, we perform both inter-group and intra-group assessment of the outcome of this policy. The former analysis is directed to investigate a differentiated impact of R\&D grants across differently funded firms, and is presented alongside utilization of the categorical matching method. The latter analysis investigates the implications of the current modulation of public intervention for similarly funded firms. Implemented by means of a continuous treatment evaluation method, the intra-group assessment allows us to investigate the likelihood of crowding-in and crowding-out effects within each tercile along the distribution of the public R\&D support grant. Both methods are coupled with the DID approach to account for unobserved heterogeneity and results strengthened by a rich dataset featuring comprehensive information on the pre-treatment variables. In addition, exploiting the exogenous variation due to the sharp change in R\&D tax credit policy that occurred in 2004, we compare treatment effects on growth of R\&D private expenditure between before- and after-reform periods, and therefore we identify the effects of such a policy change introduced by the government.

Our results show that substitution between private and public funds may occur, especially for mediumhigh levels of public subsidies, and under the regime of R\&D tax credit. Recipients of larger doses appear not to outperform or to perform worse than recipients of lower doses or non-recipient firms. Crowding-out seems stronger and more significant in the after-reform period as reported in both the propensity score and exact matching analysis performed by year. In addition, we find evidence of more extensive negative effects for firms employing fewer than 100 employees or operating in low R\&D intensive industries. When analyzing the intratercile distribution of public funds under $\mathrm{R} \& \mathrm{D}$ tax credit regime, we highlight a considerable reduction in the growth of private R\&D expenditure among medium-high subsidy recipients, whereas additionality effects are found for a few top beneficiary companies (above EUR 10 million). In the sample of fully supported recipients, it seems to emerge - on average - that firms receiving subsidies between EUR 145 thousand and 1.8 million exhibit significant lower private contribution with respect to their counterfactual units. Subsidyonly recipients instead show significant substitution of private with public R\&D resources for subsidy doses between EUR 20-55 thousand. Interestingly, when dividing the sample in before- and after-reform periods, we find that crowding-out effects seem to persist solely for recipients of subsidies under tax credit incentives after the 2004 reform.

Overall, our findings appear to suggest a substantial re-design of both the modulation and targeting of the public R\&D subsidy policy, especially under R\&D tax credit regime. Indeed, the substitution effects emerging from the inter-tercile and funded versus unfunded comparisons would motivate a better targeting of the recipient firms, especially among small and medium size firms and in low R\&D intense industries. Concerning the modulation of the public R\&D subsidy provision, it appears opportune to move resources from medium-high to top beneficiary recipients to boost the growth of private R\&D expenditure and rise the 
private contribution to R\&D in the economy. Furthermore, the distinction between fully funded from subsidyonly recipient firms underlines the importance of accounting for "hidden treatments" that may otherwise affect the policy evaluation and favor misleading implications. In addition, the 2004 reform of R\&D tax credit appears to have lowered the effectiveness of public R\&D funding. Although this result shed some lights on the effects of the 2004 reform, it also asks for further research to investigate the opportune mix of such R\&D policy tools. Finally, it is worth underlining that a potential limitation of our study is due to the fact that we do not observe companies with fewer than 20 employees in the manufacturing industries, a significant proportion of the French firm population.

This overall assessment indicates that an ex-post evaluation of the targets of an R\&D policy is desirable, if not necessary in a time of downturns or economic stagnation. In fact, if R\&D funding is seen as a valid policy instrument to support companies hit hard by a crisis and facing financial restrictions, it is inevitable that public resources should not be re-directed away from risky and promising research projects toward companies that would likely perform equally well without this funding. 


\section{Acknowledgments}

The authors appreciate helpful comments by two anonymous referees and the editor, Maryann Feldman, and thank Dominique Foray, Jacques Mairesse, Frédérique Sachwald, as well as participants at numerous seminars and conferences for their useful comments and suggestions. The authors are grateful to the statistical service of the Département des études statistiques as well as to the Service de l'Innovation, du Transfert de technologie et de l'Action régionale at the Ministère de l'enseignement supérieur et de la recherche for the access to the data. The content of this article does not however reflect the official opinion of the Ministère de l'enseignement supérieur et de la recherche. Responsibility for the information and views set out in the article lies entirely with the authors. 


\section{References}

[1] Abadie, A., Herr, J.L., Imbens, G.W., Drukker, D.M., 2004. NNMATCH: Stata module to compute nearest-neighbor bias-corrected estimators. Statistical Software Components.

[2] Aerts, K., Czarnitzki, D., 2004. Using Innovation Survey Data to Evaluate R\&D Policy: The Case of Belgium. ZEW Discussion Paper No. 04-55, Mannheim.

[3] Aerts, K., Czarnitzki D., 2006. The Impact of Public R\&D Funding in Flanders. Brussels, Belgium: IWT Study No. 54 .

[4] Aerts, K., Schmidt, T., 2008. Two for the Price of One? On Additionality Effects of R\&D Subsidies: A Comparison between Flanders and Germany. Research Policy 37(5), 806-822.

[5] Almus, M., Czarnitzki, D., 2003. The Effects of Public R\&D Subsidies on Firms' Innovation Activities: The Case of Eastern Germany. Journal of Business and Economic Statistics, 21(2), 226-236.

[6] Alvarez-Pelaez, M.J., Groth, C., 2005. Too little or too much R\&D? European Economic Review, 49(2), $437-456$.

[7] Archibugi, D., Filippetti A., Frenz, M., 2013. Economic crisis and innovation: Is destruction prevailing over accumulation? Research Policy, 42(2), 303-314.

[8] Autio, E, Rannikko, H., 2016. Retaining winners: Can policy boost high-growth entrepreneurship? Research Policy, 45(1), 42-55.

[9] Bernard, A., Jensen, B., 1999. Exceptional Exporter Performance: Cause, Effect, or Both? Journal of International Economics, 47, 1-25.

[10] Bia, M., Mattei, A., 2008. A STATA Package for the Estimation of the Dose-Response Function through Adjustment for the Generalized Propensity Score.The Stata Journal, 8(3), 354-373.

[11] Blanes, J.V., Busom, I., 2004. Who participates in R\&D subsidy programs?: The case of Spanish manufacturing firms. Research policy, 33(10), 1459-1476.

[12] Blundell, R., Dias, M.C., 2000. Evaluation Methods for Non-Experimental Data. Fiscal Studies, 231(4), 427-468.

[13] Blundell, R., Dias, M.C., 2009. Alternative approaches to evaluation in empirical microeconomics. Journal of Human Resources, 44(3), 565-640. 
[14] Buisseret, T.J., Cameron, H., Georghiou, L., 1995. What difference does it make? Additionality in the public support of R\&D in large firms. International Journal of Technology Management, 10, 587-600.

[15] Busom, I., 2000. An empirical evaluation of the effects of R\&D subsidies. Economics of Innovation and New Technology, 9(2), 111-148.

[16] Castellacci, F., Lie, C.M., 2015. Do the effects of R\&D tax credits vary across industries? A metaregression analysis. Research Policy, 44(4), 819-832.

[17] Czarnitzki, D., Fier, A., 2001. Do R\&D Subsidies Matter? Evidence for the German Service Sector. ZEW Discussion Paper No. 01-19, Mannheim.

[18] Czarnitzki, D., Licht, G., 2006. Additionality of public R\&D grants in a transition economy. Economics of Transition, 14(1), 101-131.

[19] David, P.A., Hall, B.H., Toole, A.A., 2000. Is public R\&D a complement or substitute for private R\&D? A review of the econometric evidence. Research Policy, 29(4), 497-529.

[20] Diamond, A.M., 1999. Does Funderal Funding "Crowd In" private funding of science?. Comtemporary Economic Policy, 17(4), 423-431.

[21] Dimos, C., Pugh, G., 2016. The effectiveness of R\&D subsidies: A meta-regression analysis of the evaluation literature. Research Policy, 45(1), 797-815.

[22] Duguet, E., 2004. Are R\&D Subsidies a Substitute or a Complement to Privately Funded R\&D? An Econometric Analysis at the Firm Level. Revue d'Economie Politique, 114(2), 245-274.

[23] Duguet, E., 2012. The effect of the incremental R\&D tax credit on the private funding of $R \& D$ an econometric evaluation on French firm level data. Revue d'économie Politique, 122(3), 405-435.

[24] Filippetti, A., Archibugi, D., 2011. Innovation in times of crisis: National Systems of Innovation, structure, and demand. Research Policy, 40(2), 179-192.

[25] Galí, J., 1994. Government size and macroeconomic stability. European Economic Review, 38, 17-132.

[26] Garca-Quevedo, J., 2004. Do public subsidies complement business R\&D?: A Meta-Analysis of the Econometric Evidence. Kyklos, 57, 87-102.

[27] Garicano, L., Lelarge, C., Van Reenen, J., 2013. Firm size distortions and the productivity distribution: Evidence from France. NBER Working Paper No. 18841. 
[28] Gonzalez, X., Jaumandreu, J., Pazo C., 2005. Barriers to innovation and subsidy effectiveness. The Rand Journal of Economics, 36(4), 930-950.

[29] Gonzalez, X., Pazo, C., 2008. Do public subsidies stimulate private R\&D spending?. Research Policy, $37(3), 371-389$.

[30] Guellec, D., Van Pottelsberghe De La Potterie, B., 2003. The impact of public R\&D expenditure on business R\&D. Economics of Innovation and New Technology, 12(3), 225-243.

[31] Guerzoni, M., Raiteri, E., 2015. Demand-side vs. supply-side technology policies: Hidden treatment and new empirical evidence on the policy mix. Research Policy, 44(3), 726-747.

[32] Görg, H., Henry, M., Strobl, E., 2008. Grant support and exporting activity. The Review of Economics and Statistics, 90(1), 168-174.

[33] Heckman, J., Ichimura, H., Smith, J., Todd, P., 1998. Characterizing Selection Bias Using Experimental Data. Econometrica, 66(5), 1017-1098.

[34] Heijs, J., Herrera, L., 2004. The distribution of R\&D subsidies and its effect on the final outcome of innovation policy. Working paper Instituto de Analisis Industrial y Financiero 46, Madrid.

[35] Hirano, K., Imbens, G., 2004. The propensity score with continuous treatments. Applied Bayesian Modeling and Causal Inference from Incomplete-Data Perspectives, 73-84 (A. Gelman \& X.L. Meng, Eds.). New York: Wiley.

[36] Hottenrott, H., Lopes Bento, C., Veugelers, R., 2014. Direct and cross-scheme effects in a research and development subsidy program. DICE Discussion Paper No. 152.

[37] Hussinger, K., 2008. R\&D and Subsidies at the Firm Level: An Application of Parametric and SemiParametric Two-Step Selection Models. Journal of Applied Econometrics, 23(6), 729-747.

[38] Imbens, G.W., 2000. The role of the propensity score in estimating doseresponse functions. Biometrika, 83, 706-710.

[39] Imbens, G.W., Wooldridge, J.M., 2009. New developments in econometrics. Lecture Notes, CEMMAP, UCL2009b.

[40] Lach, S., 2002. Do R\&D subsidies stimulate or displace private R\&D? Evidence from Israel. Journal of Industrial Economics, 50.4, 369-390. 
[41] Lechner, M., 2001. Identication and estimation of causal eects of multiple treatments under the conditional independence assumption, in M. Lechner and F. Pfeier (eds., 2001), Econometric Evaluation of Active Labour Market Policies, Heidelberg: Physica, 43-58.

[42] Lechner, M., 2004. Sequential Matching Estimation of Dynamic Causal Models. IZA Discussion Paper No. 1042.

[43] Leuven, E., Sianesi, B., 2014. PSMATCH2: Stata module to perform full Mahalanobis and propensity score matching, common support graphing, and covariate imbalance testing. Statistical Software Components.

[44] Lhuillery, S., 1996. Problems involved in designing and implementing R\&D tax incentive schemes, in Fiscal Measures to Promote R\&D and Innovation. OECD, CEMI-CHAPTER-2006-012, 38-57.

[45] Lööf, H., Heshmati, A., 2005. The impact of public funds on private R\&D investment: New evidence from a firm-level innovation study. In: A. Heshmati, Y. B. Sohn \& Y. R. Kim (Eds), Commercialisation and Transfer of Technology: Major Country Case Studies (Nova Science Publishers).

[46] Melitz, M.J., 2003. The Impact of Trade on Intra-Industry Reallocations and Aggregate Industry Productivity. Econometrica, 71, 1695-1725.

[47] Montmartin, B., Herrera, M., 2015. Internal and external effects of R\&D subsidies and fiscal incentives: Empirical evidence using spatial dynamic panel models. Research Policy, 44(5), 1065-1079.

[48] Montmartin, B., and Massard, N., 2015. Is financial support for private R\&D always justified? A discussion based on the literature on growth. Journal of Economic Surveys, 29(3), 479-505.

[49] OECD, 2002. Proposed Standard Practice for Surveys for Research and Experimental Development. Frascati Manual 2002, OECD, Paris.

[50] OECD, 2009. Science, Technology and Industry Scoreboard. OECD, Paris.

[51] OECD, 2013. Science, Technology and Industry Scoreboard. OECD, Paris.

[52] Reis, A.B., Sequeira, T.N., 2007. Human Capital and Overinvestment in R\&D. The Scandinavian Journal of Economics, 109(3), 573-591.

[53] Rosenbaum, P.R., Rubin, D.B., 1983. Assessing Sensitivity to an Unobserved Binary Covariate in an Observational Study With Binary Outcome. Journal of the Royal Statistical Society, 45(2), 212-218. 
[54] Suetens, S., 2002. R\&D subsidies and production effects of R\&D personnel: evidence from the Flemish region. CESIT Discussion Paper 2002/03, Antwerp.

[55] Temple, J., 2003. The long-run implications of growth theories. Journal of Economic Surveys, 17(3), 497-510.

[56] Wallsten, S.J., 2000. The effects of government-industry R\&D programs on private R\&D: the case of the Small Business Innovation Research Program. RAND Journal of Economics, 31(1), 82-100. 
Table 1: Descriptive Statistics: Recipients vs Non Recipients

\begin{tabular}{|c|c|c|c|c|c|c|c|c|c|}
\hline & \multicolumn{3}{|c|}{ Subsidy Recipients } & \multicolumn{3}{|c|}{ Subsidy and Tax Credit Recipients } & \multicolumn{3}{|c|}{ Non Recipients } \\
\hline Variable & mean & st.dev. & $\mathrm{N}$ & mean & st.dev. & $\mathrm{N}$ & mean & st.dev. & $\mathrm{N}$ \\
\hline \multicolumn{10}{|l|}{ Treatment variables } \\
\hline subsidy & $5,150.724$ & $29,415.905$ & 2,535 & $5,409.341$ & $29,285.294$ & 2,078 & 0 & 0 & 7,556 \\
\hline tax credit & 0 & 0 & 2,535 & $1,890.852$ & $5,398.443$ & 2,078 & 0 & 0 & 7,556 \\
\hline \multicolumn{10}{|l|}{ Outcome variables } \\
\hline private R\&D & $25,978.198$ & $104,239.36$ & 2,535 & $30,650.182$ & $106,742.714$ & 2,078 & $5,144.934$ & $17,490.953$ & 7,556 \\
\hline $\log$ of private $R \& D$ & 7.978 & 2.072 & 2,535 & 7.997 & 2.437 & 2,078 & 7.23 & 1.509 & 7,556 \\
\hline growth of private R\&D & 0.024 & 1.017 & 2,535 & -0.098 & 1.326 & 2,078 & 0.018 & 0.595 & 7,556 \\
\hline \multicolumn{10}{|l|}{ Pre-treatment variables } \\
\hline subsidy_2nd & 0.239 & 0.427 & 2,535 & 0.228 & 0.419 & 2,078 & 0.035 & 0.184 & 7,556 \\
\hline subsidy_3rd & 0.323 & 0.468 & 2,535 & 0.311 & 0.463 & 2,078 & 0.012 & 0.111 & 7,556 \\
\hline tax credit_2nd & 0.082 & 0.274 & 2,535 & 0.217 & 0.412 & 2,078 & 0.065 & 0.246 & 7,556 \\
\hline tax credit_3rd & 0.105 & 0.307 & 2,535 & 0.376 & 0.485 & 2,078 & 0.051 & 0.221 & 7,556 \\
\hline other subsidy_2nd & 0.225 & 0.418 & 2,535 & 0.219 & 0.414 & 2,078 & 0.181 & 0.385 & 7,556 \\
\hline other subsidy_3rd & 0.415 & 0.493 & 2,535 & 0.43 & 0.495 & 2,078 & 0.139 & 0.346 & 7,556 \\
\hline private $R \& D \_2 n d$ & 0.069 & 0.254 & 2,535 & 0.063 & 0.242 & 2,078 & 0.103 & 0.304 & 7,556 \\
\hline private R\&D_3rd & 0.083 & 0.276 & 2,535 & 0.059 & 0.235 & 2,078 & 0.11 & 0.313 & 7,556 \\
\hline private R\&D_4th & 0.078 & 0.268 & 2,535 & 0.078 & 0.269 & 2,078 & 0.109 & 0.311 & 7,556 \\
\hline private R\&D_5th & 0.087 & 0.282 & 2,535 & 0.078 & 0.269 & 2,078 & 0.102 & 0.303 & 7,556 \\
\hline private R\&D_6th & 0.088 & 0.283 & 2,535 & 0.085 & 0.278 & 2,078 & 0.108 & 0.31 & 7,556 \\
\hline private R\&D_7th & 0.098 & 0.298 & 2,535 & 0.088 & 0.283 & 2,078 & 0.114 & 0.317 & 7,556 \\
\hline private R\&D_8th & 0.105 & 0.307 & 2,535 & 0.102 & 0.302 & 2,078 & 0.109 & 0.312 & 7,556 \\
\hline private R\&D_9th & 0.138 & 0.345 & 2,535 & 0.133 & 0.34 & 2,078 & 0.092 & 0.289 & 7,556 \\
\hline private R\&D_10th & 0.192 & 0.394 & 2,535 & 0.248 & 0.432 & 2,078 & 0.062 & 0.241 & 7,556 \\
\hline cash & 0.811 & 0.392 & 2,535 & 0.810 & 0.392 & 2,078 & 0.851 & 0.357 & 7,556 \\
\hline R\&D VA ratio & 0.133 & 9.65 & 2,535 & 0.582 & 9.881 & 2,078 & 0.092 & 3.533 & 7,556 \\
\hline export intensity & 0.369 & 0.284 & 2,535 & 0.412 & 0.295 & 2,078 & 0.355 & 0.279 & 7,556 \\
\hline foreign ownership & 0.28 & 0.449 & 2,535 & 0.288 & 0.453 & 2,078 & 0.496 & 0.5 & 7,556 \\
\hline $\operatorname{size}(20-50)$ & 0.085 & 0.279 & 2,535 & 0.084 & 0.278 & 2,078 & 0.079 & 0.27 & 7,556 \\
\hline $\operatorname{size}(50-100)$ & 0.124 & 0.329 & 2,535 & 0.124 & 0.329 & 2,078 & 0.118 & 0.322 & 7,556 \\
\hline $\operatorname{size}(100-500)$ & 0.373 & 0.484 & 2,535 & 0.347 & 0.476 & 2,078 & 0.485 & 0.5 & 7,556 \\
\hline $\operatorname{size}(>500)$ & 0.411 & 0.492 & 2,535 & 0.439 & 0.496 & 2,078 & 0.309 & 0.462 & 7,556 \\
\hline
\end{tabular}

Note: Monetary values are reported in thousands of euros and deflated at 2000 year price level. 
Table 2: Descriptive Statistics: Terciles of Subsidy Recipients

\begin{tabular}{|c|c|c|c|c|c|c|c|c|c|}
\hline \multirow[b]{2}{*}{ Variable } & \multicolumn{3}{|c|}{ 1st Tercile } & \multicolumn{3}{|c|}{ 2nd Tercile } & \multicolumn{3}{|c|}{ 3rd Tercile } \\
\hline & mean & st.dev. & $\mathrm{N}$ & mean & st.dev. & $\mathrm{N}$ & mean & st.dev. & $\mathrm{N}$ \\
\hline \multicolumn{10}{|l|}{ Treatment variables } \\
\hline subsidy & 19.119 & 11.113 & 813 & 111.793 & 58.225 & 802 & $14,078.136$ & $47,546.56$ & 920 \\
\hline tax credit & 0 & 0 & 813 & 0 & 0 & 802 & 0 & 0 & 920 \\
\hline \multicolumn{10}{|l|}{ Outcome variables } \\
\hline private $R \& D$ & $4,889.533$ & $14,105.364$ & 813 & $8,752.616$ & $22,634.597$ & 802 & $59,630.374$ & $165,989.341$ & 920 \\
\hline $\log$ of private $R \& D$ & 7.257 & 1.485 & 813 & 7.58 & 1.753 & 802 & 8.961 & 2.377 & 920 \\
\hline growth of private $R \& D$ & 0.051 & 0.63 & 813 & 0.001 & 0.77 & 802 & 0.021 & 1.408 & 920 \\
\hline \multicolumn{10}{|l|}{ Pre-treatment variables } \\
\hline subsidy_2nd & 0.171 & 0.377 & 813 & 0.436 & 0.496 & 802 & 0.127 & 0.333 & 920 \\
\hline subsidy_3rd & 0.036 & 0.186 & 813 & 0.132 & 0.339 & 802 & 0.742 & 0.438 & 920 \\
\hline tax credit_2nd & 0.107 & 0.309 & 813 & 0.086 & 0.281 & 802 & 0.055 & 0.229 & 920 \\
\hline tax credit_3rd & 0.07 & 0.255 & 813 & 0.086 & 0.281 & 802 & 0.153 & 0.36 & 920 \\
\hline other subsidy_2nd & 0.327 & 0.469 & 813 & 0.228 & 0.42 & 802 & 0.132 & 0.338 & 920 \\
\hline other subsidy_3rd & 0.252 & 0.435 & 813 & 0.362 & 0.481 & 802 & 0.604 & 0.489 & 920 \\
\hline private R\&D_2nd & 0.109 & 0.312 & 813 & 0.075 & 0.263 & 802 & 0.028 & 0.166 & 920 \\
\hline private R\&D_3rd & 0.13 & 0.337 & 813 & 0.102 & 0.303 & 802 & 0.025 & 0.156 & 920 \\
\hline private R\&D_4th & 0.106 & 0.308 & 813 & 0.096 & 0.295 & 802 & 0.038 & 0.191 & 920 \\
\hline private R\&D_5th & 0.107 & 0.309 & 813 & 0.111 & 0.314 & 802 & 0.048 & 0.214 & 920 \\
\hline private R\&D_6th & 0.103 & 0.305 & 813 & 0.102 & 0.303 & 802 & 0.061 & 0.239 & 920 \\
\hline private R\&D_7th & 0.106 & 0.308 & 813 & 0.102 & 0.303 & 802 & 0.088 & 0.284 & 920 \\
\hline private R\&D_8th & 0.114 & 0.318 & 813 & 0.097 & 0.296 & 802 & 0.104 & 0.306 & 920 \\
\hline private R\&D_9th & 0.082 & 0.275 & 813 & 0.12 & 0.325 & 802 & 0.202 & 0.402 & 920 \\
\hline private R\&D_10th & 0.068 & 0.251 & 813 & 0.127 & 0.333 & 802 & 0.359 & 0.48 & 920 \\
\hline cashl & 0.868 & 0.338 & 813 & 0.813 & 0.39 & 802 & 0.758 & 0.429 & 920 \\
\hline R\&D VA ratio & 0.1 & 0.971 & 813 & 0.217 & 0.834 & 802 & 0.088 & 15.979 & 920 \\
\hline export intensity & 0.365 & 0.282 & 813 & 0.36 & 0.281 & 802 & 0.38 & 0.289 & 920 \\
\hline foreign ownership & 0.332 & 0.471 & 813 & 0.297 & 0.457 & 802 & 0.221 & 0.415 & 920 \\
\hline $\operatorname{size}(20-50)$ & 0.107 & 0.309 & 813 & 0.1 & 0.3 & 802 & 0.052 & 0.222 & 920 \\
\hline $\operatorname{size}(50-100)$ & 0.154 & 0.361 & 813 & 0.118 & 0.323 & 802 & 0.102 & 0.303 & 920 \\
\hline $\operatorname{size}(100-500)$ & 0.416 & 0.493 & 813 & 0.415 & 0.493 & 802 & 0.298 & 0.458 & 920 \\
\hline $\operatorname{size}(>500)$ & 0.316 & 0.465 & 813 & 0.355 & 0.479 & 802 & 0.542 & 0.498 & 920 \\
\hline
\end{tabular}

Note: Monetary values are reported in thousands of euros and deflated at 2000 year price level. 
Table 3: Descriptive Statistics: Terciles of Subsidy and Tax Credit Recipients

\begin{tabular}{|c|c|c|c|c|c|c|c|c|c|}
\hline & \multicolumn{3}{|c|}{ 1st Tercile } & \multicolumn{3}{|c|}{ 2nd Tercile } & \multicolumn{3}{|c|}{ 3rd Tercile } \\
\hline Variable & mean & st.dev. & $\mathrm{N}$ & mean & st.dev. & $\mathrm{N}$ & mean & st.dev. & $\mathrm{N}$ \\
\hline \multicolumn{10}{|l|}{ Treatment variables } \\
\hline subsidy & 19.641 & 11.704 & 658 & 112.228 & 55.495 & 652 & $14,524.106$ & $46,802.292$ & 768 \\
\hline tax credit & 507.863 & $1,090.91$ & 658 & 817.271 & $2,311.269$ & 652 & $3,987.182$ & $8,145.181$ & 768 \\
\hline \multicolumn{10}{|l|}{ Outcome variables } \\
\hline private $R \& D$ & $5,936.985$ & $16,721.528$ & 658 & $12,573.834$ & $59,484.453$ & 652 & $67,169.795$ & $159,607.449$ & 768 \\
\hline $\log$ of private $R \& D$ & 7.333 & 1.607 & 658 & 7.486 & 2.126 & 652 & 8.999 & 2.903 & 768 \\
\hline growth of private $R \& D$ & -0.002 & 0.62 & 658 & -0.136 & 0.916 & 652 & -0.149 & 1.925 & 768 \\
\hline \multicolumn{10}{|l|}{ Pre-treatment variables } \\
\hline subsidy_2nd & 0.164 & 0.371 & 658 & 0.399 & 0.49 & 652 & 0.137 & 0.344 & 768 \\
\hline subsidy_3rd & 0.036 & 0.188 & 658 & 0.14 & 0.347 & 652 & 0.693 & 0.462 & 768 \\
\hline tax credit_2nd & 0.267 & 0.443 & 658 & 0.252 & 0.434 & 652 & 0.145 & 0.352 & 768 \\
\hline tax credit_3rd & 0.242 & 0.428 & 658 & 0.299 & 0.458 & 652 & 0.557 & 0.497 & 768 \\
\hline other subsidy_2nd & 0.331 & 0.471 & 658 & 0.248 & 0.432 & 652 & 0.098 & 0.297 & 768 \\
\hline other subsidy_3rd & 0.226 & 0.419 & 658 & 0.377 & 0.485 & 652 & 0.648 & 0.478 & 768 \\
\hline private R\&D_2nd & 0.106 & 0.309 & 658 & 0.069 & 0.254 & 652 & 0.02 & 0.138 & 768 \\
\hline private $R \& D \_3 r d$ & 0.09 & 0.286 & 658 & 0.067 & 0.251 & 652 & 0.025 & 0.155 & 768 \\
\hline private R\&D_4th & 0.091 & 0.288 & 658 & 0.117 & 0.321 & 652 & 0.035 & 0.184 & 768 \\
\hline private $R \& D \_5$ th & 0.103 & 0.305 & 658 & 0.097 & 0.296 & 652 & 0.042 & 0.2 & 768 \\
\hline private R\&D_6th & 0.126 & 0.332 & 658 & 0.087 & 0.283 & 652 & 0.047 & 0.212 & 768 \\
\hline private $R \& D$ _th & 0.1 & 0.301 & 658 & 0.095 & 0.294 & 652 & 0.072 & 0.258 & 768 \\
\hline private R\&D_8th & 0.116 & 0.32 & 658 & 0.121 & 0.327 & 652 & 0.073 & 0.26 & 768 \\
\hline private R\&D_9th & 0.116 & 0.32 & 658 & 0.121 & 0.327 & 652 & 0.159 & 0.366 & 768 \\
\hline private R\&D_10th & 0.085 & 0.279 & 658 & 0.144 & 0.352 & 652 & 0.475 & 0.5 & 768 \\
\hline cashl & 0.872 & 0.334 & 658 & 0.802 & 0.399 & 652 & 0.763 & 0.426 & 768 \\
\hline R\&D VA ratio & 0.795 & 17.107 & 658 & 0.266 & 0.733 & 652 & 0.668 & 3.621 & 768 \\
\hline export intensity & 0.385 & 0.293 & 658 & 0.394 & 0.297 & 652 & 0.449 & 0.292 & 768 \\
\hline foreign ownership & 0.31 & 0.463 & 658 & 0.29 & 0.454 & 652 & 0.267 & 0.443 & 768 \\
\hline $\operatorname{size}(20-50)$ & 0.112 & 0.316 & 658 & 0.106 & 0.308 & 652 & 0.042 & 0.2 & 768 \\
\hline $\operatorname{size}(50-100)$ & 0.144 & 0.352 & 658 & 0.156 & 0.364 & 652 & 0.078 & 0.269 & 768 \\
\hline $\operatorname{size}(100-500)$ & 0.41 & 0.492 & 658 & 0.397 & 0.49 & 652 & 0.25 & 0.433 & 768 \\
\hline $\operatorname{size}(>500)$ & 0.324 & 0.468 & 658 & 0.331 & 0.471 & 652 & 0.629 & 0.483 & 768 \\
\hline
\end{tabular}

Note: Monetary values are reported in thousands of euros and deflated at 2000 year price level. 
Table 4: Pscore Matching: ATT Estimates (differences in log-levels of private R\&D)

\begin{tabular}{lcccccc}
\hline & \multicolumn{3}{c}{ Subsidy } & \multicolumn{3}{c}{ Subsidy under Tax Credit } \\
\hline & Non Recipients & Small & Medium & Non Recipients & Small & Medium \\
\hline Recipients & $0.3857^{* * *}$ & & & $0.2312^{* *}$ & & \\
& $(0.0784)$ & & & $(0.1118)$ & & \\
Small & -0.1467 & & & -0.1067 & & \\
& $(0.0933)$ & & & $(0.1105)$ & & \\
Medium & 0.0827 & $0.1861^{*}$ & & -0.0822 & 0.1249 & \\
& $(0.0980)$ & $(0.1022)$ & & $(0.1314)$ & $(0.1352)$ & \\
Large & $0.6714^{* * *}$ & $0.8153^{* * *}$ & $0.6065^{* * *}$ & $0.6173^{* * *}$ & $0.8840^{* * *}$ & $0.4274^{* *}$ \\
& $(0.1325)$ & $(0.1495)$ & $(0.1497)$ & $(0.1869)$ & $(0.2128)$ & $(0.2157)$ \\
\hline \hline
\end{tabular}

Note: We hereby report the Average Treatment on Treated. The caliper is set equal to 0.01. Significance levels: ${ }^{* * *}(1 \%),{ }^{* *}(5 \%),{ }^{*}(10 \%)$.

Table 5: Pscore Matching: ATT Estimates (differences in growth of private R\&D)

\begin{tabular}{lcccccc}
\hline & \multicolumn{2}{c}{ Subsidy } & \multicolumn{3}{c}{ Subsidy under Tax Credit } \\
\hline & Non Recipients & Small & Medium & Non Recipients & Small & Medium \\
\hline Recipients & $-0.1481^{* * *}$ & & & $-0.1894^{* * *}$ & & \\
& $(0.0389)$ & & & $(0.0515)$ & & \\
Small & -0.0572 & & & -0.0446 & & \\
& $(0.0411)$ & & & $(0.0534)$ & & \\
Medium & $-0.1007^{* *}$ & $-0.0849^{*}$ & & $-0.1359^{* *}$ & $-0.1512^{* * *}$ & \\
& $(0.0469)$ & $(0.0454)$ & & $(0.0564)$ & $(0.0595)$ & \\
Large & $-0.1783^{* *}$ & $-0.2308^{* * *}$ & -0.0114 & $-0.2558^{* *}$ & $-0.1650^{*}$ & -0.1034 \\
& $(0.0699)$ & $(0.0735)$ & $(0.0679)$ & $(0.1216)$ & $(0.0927)$ & $(0.1139)$ \\
\hline \hline
\end{tabular}

Note: We hereby report the Average Treatment on Treated. The caliper is set equal to 0.01. Significance levels: $* * *(1 \%), * *(5 \%),{ }^{*}(10 \%)$. 
Table 6: Robustness Checks - Pscore Matching: ATT Estimates (differences in growth of private $R \& D)$

\begin{tabular}{|c|c|c|c|c|c|c|}
\hline & \multicolumn{6}{|c|}{ Big Firms } \\
\hline & \multicolumn{3}{|c|}{ Subsidy } & \multicolumn{3}{|c|}{ Subsidy under Tax Credit } \\
\hline & Non Recipients & Small & Medium & Non Recipients & Small & Medium \\
\hline \multirow[t]{2}{*}{ Recipients } & $-0.0810^{* *}$ & & & $-0.1107^{*}$ & & \\
\hline & $(0.0401)$ & & & $(0.0659)$ & & \\
\hline \multirow[t]{2}{*}{ Small } & -0.0331 & & & -0.0494 & & \\
\hline & $(0.0475)$ & & & $(0.0600)$ & & \\
\hline \multirow[t]{2}{*}{ Medium } & -0.0542 & $-0.1008^{* *}$ & & -0.0368 & -0.0254 & \\
\hline & $(0.0497)$ & $(0.0498)$ & & $(0.0657)$ & $(0.0578)$ & \\
\hline \multirow[t]{5}{*}{ Large } & $-0.1582^{* *}$ & $-0.1754^{* * *}$ & 0.0152 & $-0.1813^{* *}$ & $-0.1953^{*}$ & -0.0468 \\
\hline & $(0.0762)$ & $(0.0656)$ & $(0.0724)$ & $(0.0776)$ & $(0.1044)$ & $(0.1085)$ \\
\hline & \multicolumn{6}{|c|}{ Small Firms } \\
\hline & \multicolumn{3}{|c|}{ Subsidy } & \multicolumn{3}{|c|}{ Subsidy under Tax Credit } \\
\hline & Non Recipients & Small & Medium & Non Recipients & Small & Medium \\
\hline \multirow[t]{2}{*}{ Recipients } & $-0.2241^{* * *}$ & & & $-0.3849^{* * *}$ & & \\
\hline & $(0.0798)$ & & & $(0.0859)$ & & \\
\hline \multirow[t]{2}{*}{ Small } & -0.1194 & & & -0.0451 & & \\
\hline & $(0.1024)$ & & & $(0.1190)$ & & \\
\hline \multirow[t]{2}{*}{ Medium } & -0.0831 & -0.0756 & & $-0.3653^{* *}$ & $-0.5382^{* * *}$ & \\
\hline & $(0.1052)$ & $(0.1099)$ & & $(0.1598)$ & $(0.1505)$ & \\
\hline \multirow[t]{5}{*}{ Large } & $-0.1855^{* *}$ & $-0.2381^{*}$ & -0.0381 & $-0.6434^{* *}$ & $-0.7017^{* *}$ & -0.2169 \\
\hline & $(0.0943)$ & $(0.1308)$ & $(0.1622)$ & $(0.3027)$ & $(0.2831)$ & $(0.3282)$ \\
\hline & \multicolumn{6}{|c|}{ High R\&D Industries } \\
\hline & \multicolumn{3}{|c|}{ Subsidy } & \multicolumn{3}{|c|}{ Subsidy under Tax Credit } \\
\hline & Non Recipients & Small & Medium & Non Recipients & Small & Medium \\
\hline \multirow[t]{2}{*}{ Recipients } & $-0.1233^{* *}$ & & & $-0.1567^{*}$ & & \\
\hline & $(0.0602)$ & & & $(0.0866)$ & & \\
\hline \multirow[t]{2}{*}{ Small } & -0.0118 & & & -0.0102 & & \\
\hline & $(0.0692)$ & & & $(0.0593)$ & & \\
\hline Medium & $-0.1472^{* *}$ & 0.0022 & & -0.1172 & $-0.1453^{* *}$ & \\
\hline & $(0.0715)$ & $(0.0701)$ & & $(0.0811)$ & $(0.0723)$ & \\
\hline Large & $-0.1540^{* *}$ & $-0.1706^{*}$ & -0.0776 & $-0.1959^{* *}$ & -0.0038 & 0.0227 \\
\hline & $(0.0771)$ & $(0.0909)$ & $(0.0991)$ & $(0.0909)$ & $(0.1181)$ & $(0.1314)$ \\
\hline & & & ow R\&D & Industries & & \\
\hline & & Subsidy & & Subsidy $u$ & ider $\mathrm{Tax} C r \mathrm{t}$ & \\
\hline & Non Recipients & Small & Medium & Non Recipients & Small & Medium \\
\hline Recipients & $-0.2462^{* * *}$ & & & $-0.1334^{* *}$ & & \\
\hline & $(0.0642)$ & & & $(0.0626)$ & & \\
\hline Small & $-0.2068^{* * *}$ & & & 0.0009 & & \\
\hline & $(0.0662)$ & & & $(0.0596)$ & & \\
\hline Medium & $-0.2359^{* * *}$ & -0.0599 & & $-0.1171^{* *}$ & $-0.2767^{* * *}$ & \\
\hline & $(0.0631)$ & $(0.0570)$ & & $(0.0554)$ & $(0.0922)$ & \\
\hline Large & $-0.2509^{* *}$ & -0.0772 & 0.0349 & $-0.2663^{* * *}$ & -0.0607 & $-0.2963^{*}$ \\
\hline & $(0.1058)$ & $(0.0828)$ & $(0.0857)$ & $(0.0997)$ & $(0.0857)$ & $(0.1622)$ \\
\hline & & No R\&D & from de & fence departme & & \\
\hline Recipients & $-0.1418^{* * *}$ & & & $-0.3098^{* * *}$ & & \\
\hline & $(0.0388)$ & & & $(0.0872)$ & & \\
\hline Small & -0.0593 & & & $-0.1227^{* *}$ & & \\
\hline & $(0.0448)$ & & & $(0.0584)$ & & \\
\hline Medium & $-0.1288^{* *}$ & -0.0805 & & $-0.3507^{* * *}$ & $-0.1312^{* *}$ & \\
\hline & $(0.0520)$ & $(0.0515)$ & & $(0.0718)$ & $(0.0551)$ & \\
\hline Large & $-0.2148^{* * *}$ & $-0.3435^{* * *}$ & 0.0006 & $-0.4157^{* * *}$ & $-0.1932^{* *}$ & -0.1052 \\
\hline & $(0.0746)$ & $(0.0867)$ & $(0.0763)$ & $(0.1157)$ & $(0.0845)$ & $(0.0976)$ \\
\hline
\end{tabular}

Note: "Big firms" ("Small firms") are companies with at least (fewer) than 100 employees. The subset of "high R\&D industries" include (i) Manufacture of chemicals, chemical products and man-made fibres; (ii) Manufacture of electrical and optical equipment; (iii) Manufacture of transport equipment; (iv) Public administration and defense; compulsory social security. "Low R\&D industries" are the complementary set of "high-tech R\&D industries". In the last check, we exclude R\&D financing from the Defence department. We hereby report the Average Treatment on Treated. The caliper is set equal to 0.01 . Significance levels: ${ }^{* * *}(1 \%),{ }^{* *}(5 \%), *(10 \%)$. 
Figure 1: Average Public Funding and Tax Credit

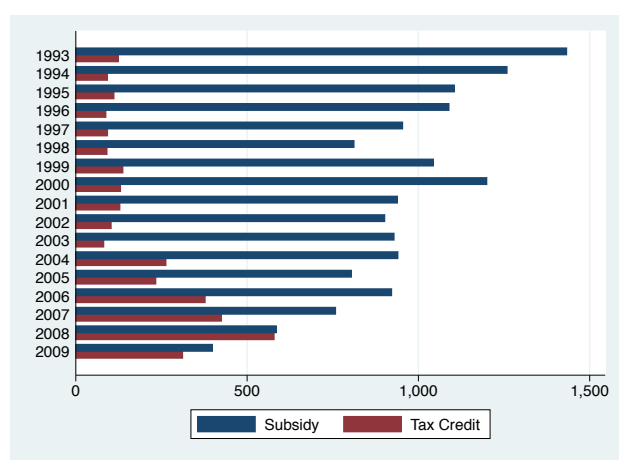

Note: All values are reported in thousands of euros and deflated at 2000 year price level.

Figure 2: Average Private R\&D Expenditure, Public Funding and Tax Credit

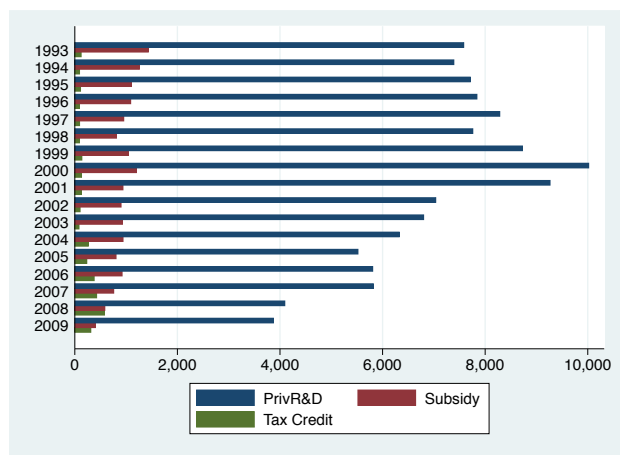

Note: All values are reported in thousands of euros and deflated at 2000 year price level.

Figure 3: Average Private R\&D Expenditure of Treated and Controls, and Subsidy

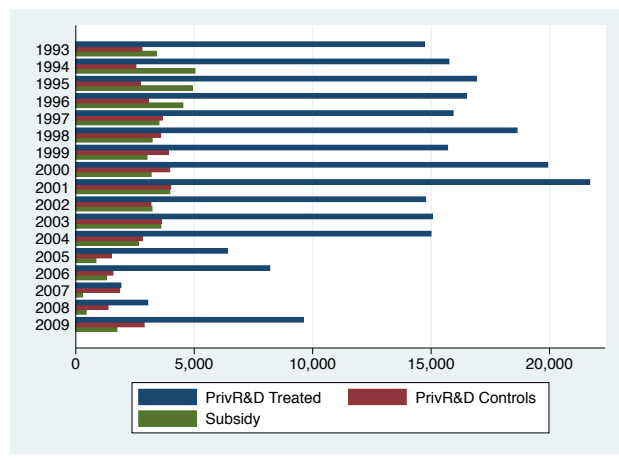

Note: All values are reported in thousands of euros and deflated at 2000 year price level. 


\section{Pscore Matching: ATT Estimates - Subsidy}

(a) Figure 4

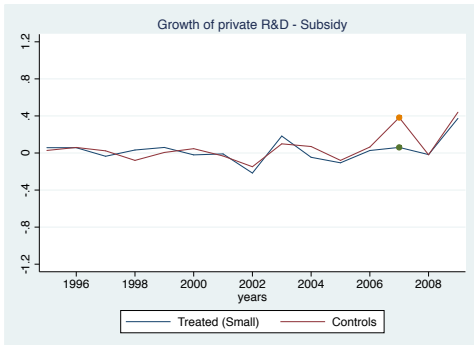

(d) Figure 7

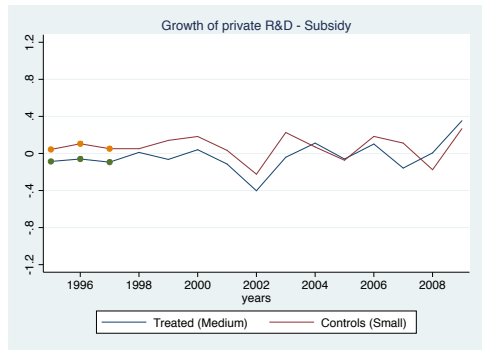

(b) Figure 5

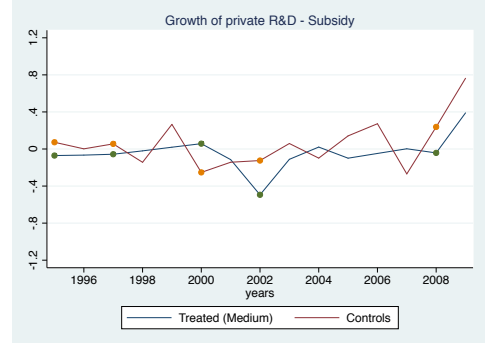

(e) Figure 8

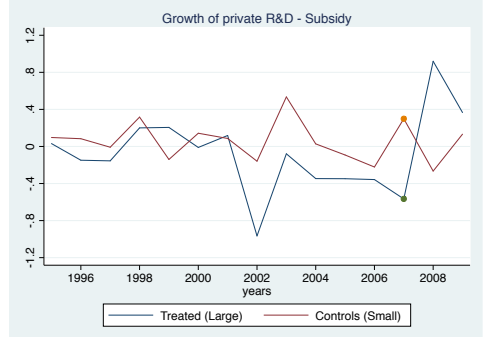

(c) Figure 6

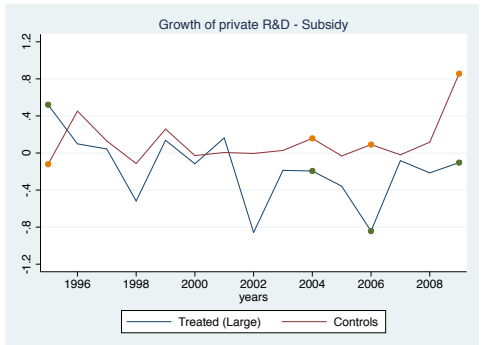

(f) Figure 9

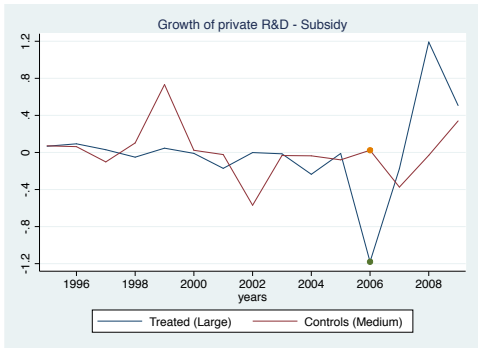

Note: Dots indicate values for treated and controls whose differences are significant (at least) at $10 \%$ level. 


\section{Pscore Matching: ATT Estimates - Subsidy under Tax Credit}

(a) Figure 10

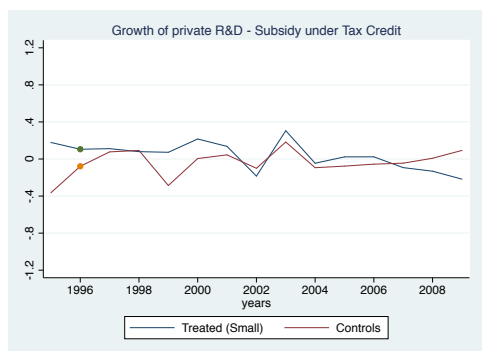

(d) Figure 13

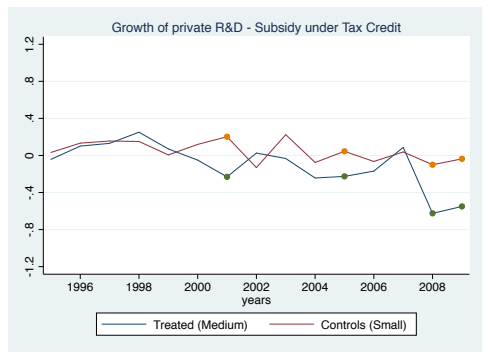

(b) Figure 11

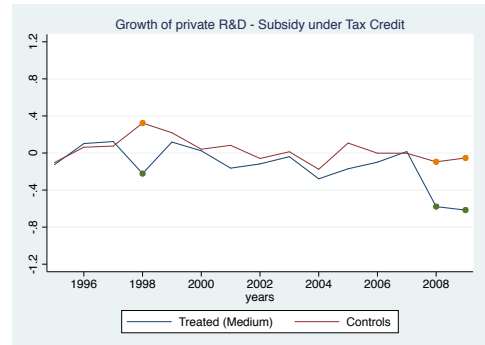

(e) Figure 14

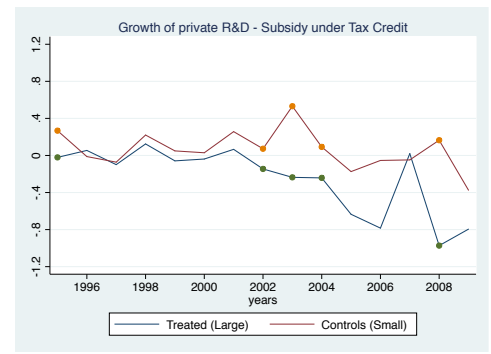

(c) Figure 12

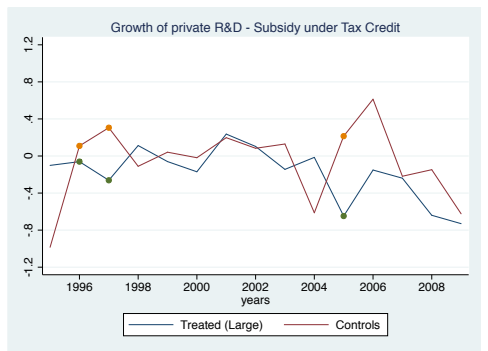

(f) Figure 15

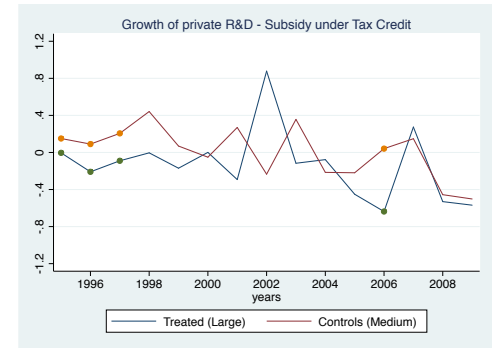

Note: Dots indicate values for treated and controls whose differences are significant (at least) at $10 \%$ level. 


\section{Continuous Treatment Matching}

(a) Figure 16

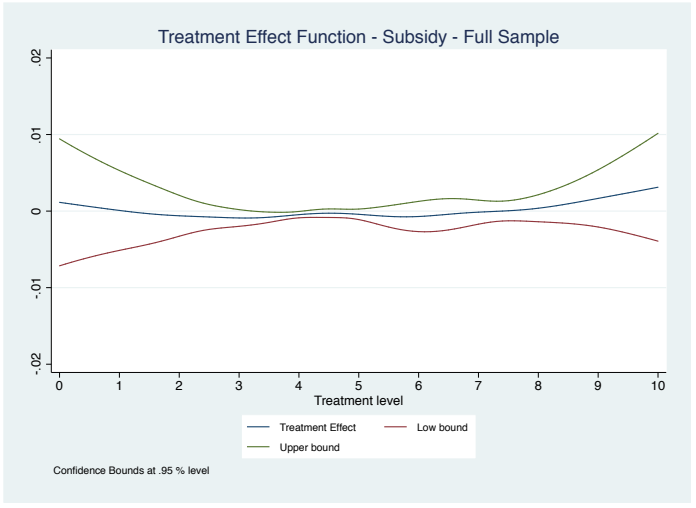

(c) Figure 18

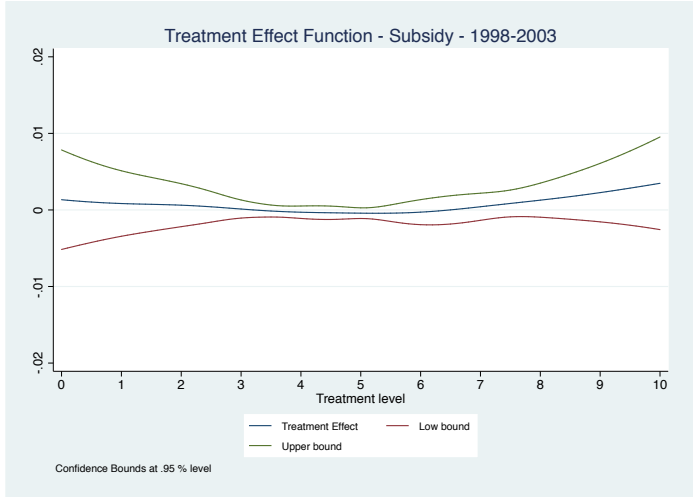

(e) Figure 20

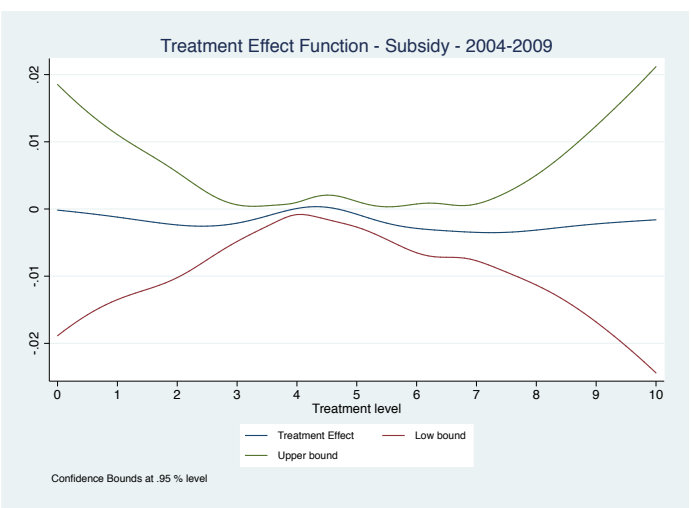

(b) Figure 17

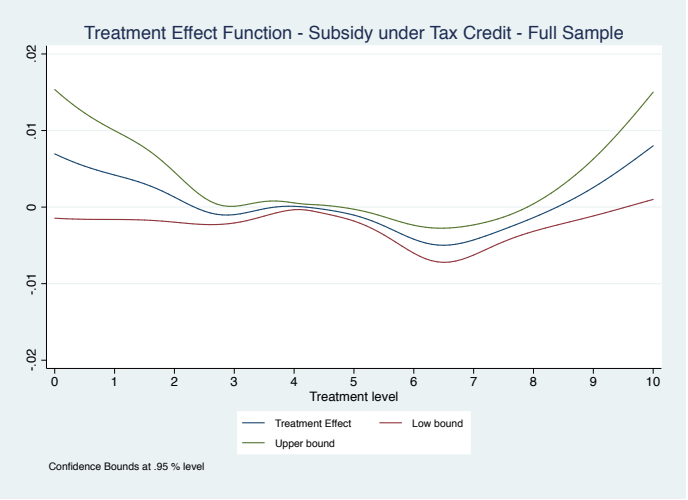

(d) Figure 19

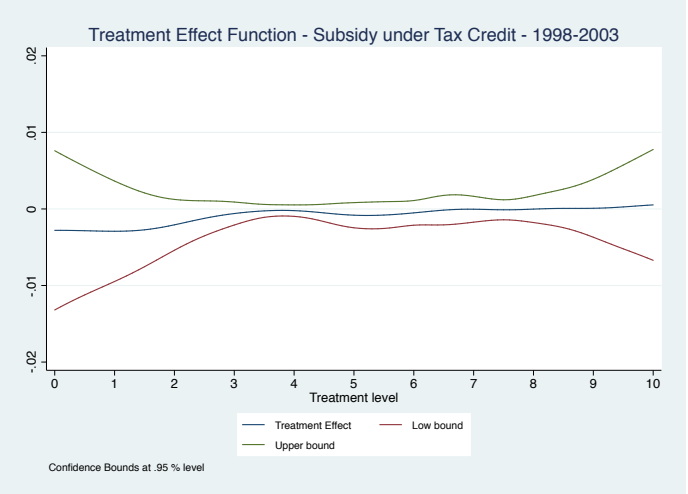

(f) Figure 21

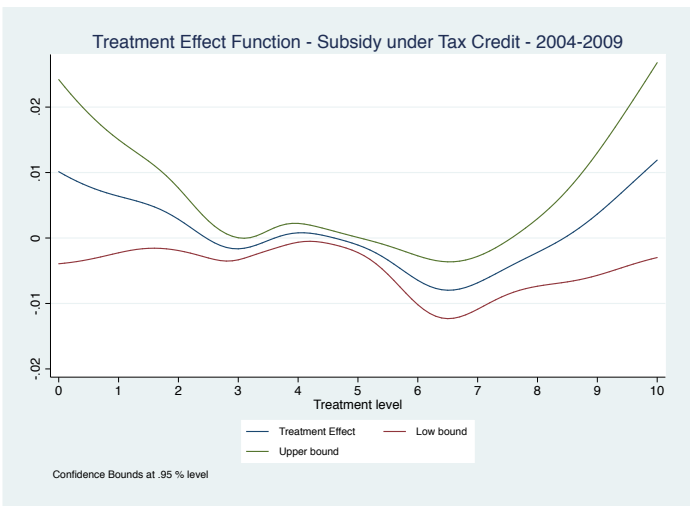




\section{Appendix A: Exact Matching}

\section{Exact Matching: ATT Estimates - Subsidy}

(a) Figure A1

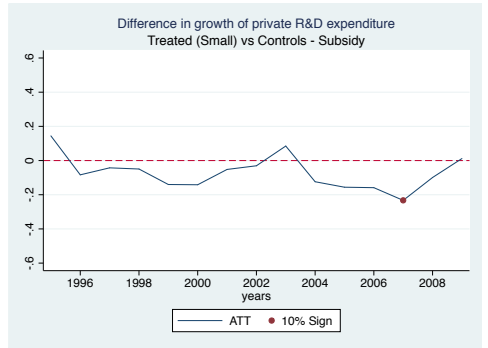

(d) Figure A4

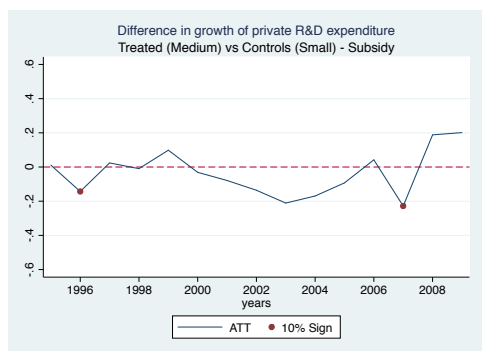

(b) Figure A2

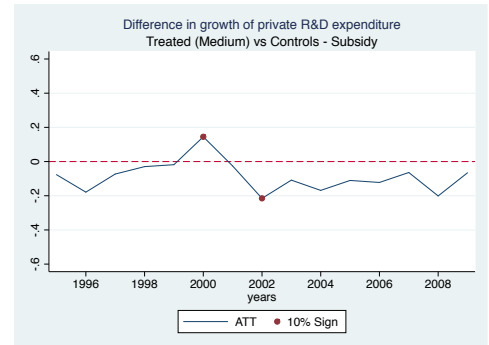

(e) Figure A5

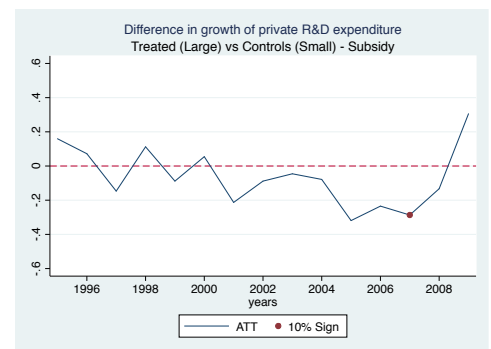

(c) Figure A3

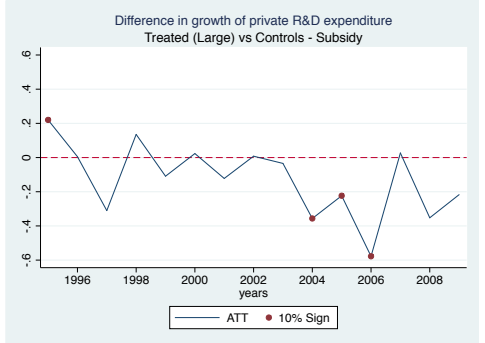

(f) Figure A6

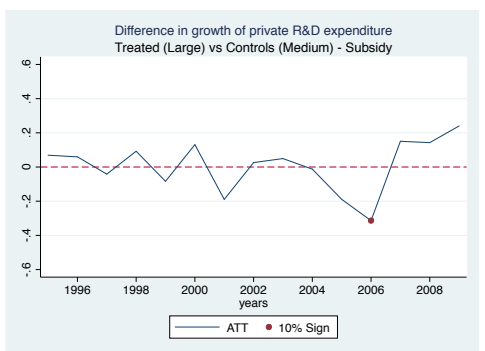

Note: Dots indicate that ATTs are significant (at least) at $10 \%$ level. 


\section{Exact Matching: ATT Estimates - Subsidy under Tax Credit}

(a) Figure A7

Difference in growth of private R\&D expenditure

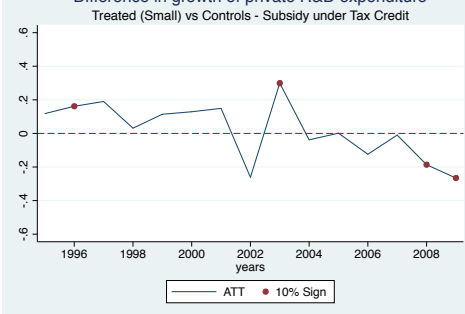

(d) Figure A10

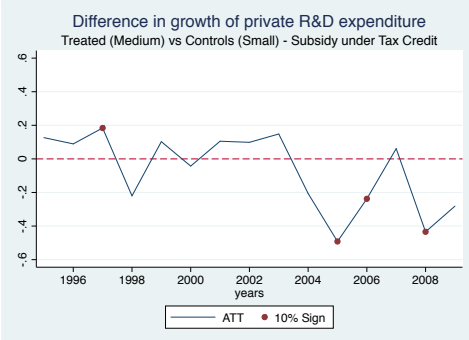

(b) Figure A8

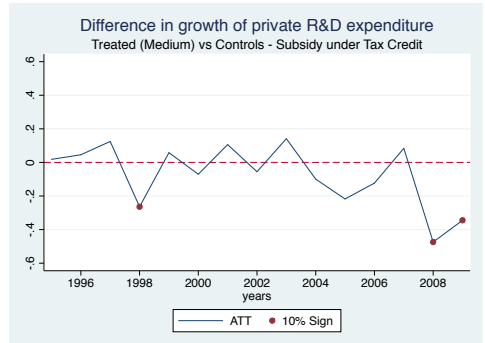

(e) Figure A11

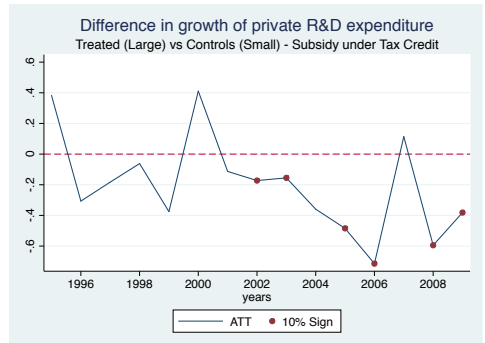

(c) Figure A9

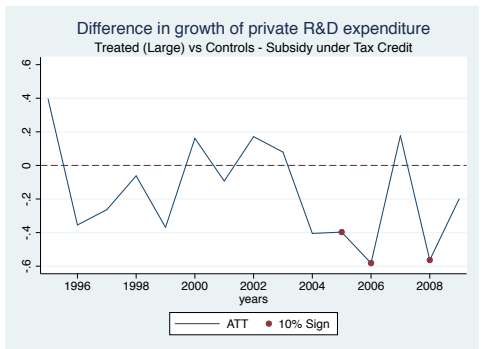

(f) Figure A12

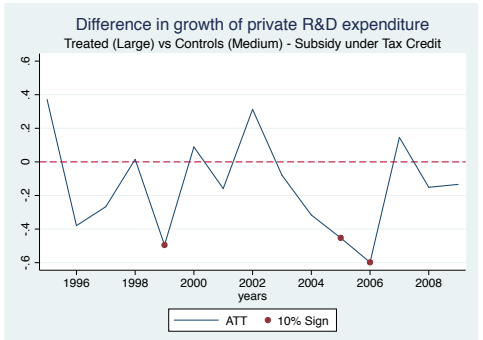

Note: Dots indicate that ATTs are significant (at least) at $10 \%$ level. 


\section{Appendix B: Continuous Treatment Matching}

Table B1: Full Sample - Treatment Effect: Differences in Growth of Private R\&D

\begin{tabular}{cc|ccc|ccc}
\hline \multicolumn{3}{c}{ Treatment } & \multicolumn{3}{c}{ Subsidy } & \multicolumn{3}{c}{ Subsidy under Tax Credit } \\
\hline Log-level & Level (thousand Euros) & Effect & St.dev. & T-stat & Effect & St.dev. & T-stat \\
\hline 0.000 & 1.000 & 0.001 & 0.004 & 0.270 & 0.007 & 0.004 & 1.622 \\
1.000 & 2.718 & 0.000 & 0.003 & 0.032 & 0.004 & 0.003 & 1.414 \\
1.500 & 4.482 & 0.000 & 0.002 & -0.171 & 0.003 & 0.002 & 1.260 \\
2.000 & 7.389 & -0.001 & 0.001 & -0.449 & 0.001 & 0.002 & 0.781 \\
2.500 & 12.182 & -0.001 & 0.001 & -0.927 & -0.001 & 0.001 & -0.600 \\
3.000 & 20.086 & -0.001 & 0.001 & -1.615 & -0.001 & 0.001 & -1.773 \\
3.500 & 33.116 & -0.001 & 0.000 & -2.345 & 0.000 & 0.001 & -0.459 \\
4.000 & 54.598 & -0.001 & 0.000 & -2.187 & 0.000 & 0.000 & 0.457 \\
4.500 & 90.017 & 0.000 & 0.000 & -0.971 & 0.000 & 0.000 & -1.090 \\
5.000 & 148.413 & 0.000 & 0.000 & -1.200 & -0.001 & 0.000 & -2.675 \\
5.500 & 244.692 & -0.001 & 0.001 & -0.973 & -0.002 & 0.001 & -4.048 \\
6.000 & 403.429 & -0.001 & 0.001 & -0.701 & -0.004 & 0.001 & -4.508 \\
6.500 & 665.142 & 0.000 & 0.001 & -0.397 & -0.005 & 0.001 & -4.381 \\
7.000 & 1096.633 & 0.000 & 0.001 & -0.174 & -0.004 & 0.001 & -4.273 \\
7.500 & 1808.042 & 0.000 & 0.001 & 0.064 & -0.003 & 0.001 & -3.549 \\
8.000 & 2980.958 & 0.000 & 0.001 & 0.415 & -0.001 & 0.001 & -1.495 \\
8.500 & 4914.769 & 0.001 & 0.001 & 0.730 & 0.000 & 0.001 & 0.316 \\
9.000 & 8103.084 & 0.002 & 0.002 & 0.869 & 0.003 & 0.002 & 1.350 \\
9.500 & 13359.727 & 0.002 & 0.003 & 0.883 & 0.005 & 0.003 & 1.926 \\
10.000 & 22026.465 & 0.003 & 0.004 & 0.868 & 0.008 & 0.004 & 2.239 \\
\hline \hline
\end{tabular}

Note: Treatment effects (Effect) refer to a dose increase of EUR 1,000. Monetary values are deflated at 2000 year price level. 
Table B2: Period 1998 - 2003 - Treatment Effect: Differences in Growth of Private R\&D

\begin{tabular}{cc|ccc|ccc}
\hline \multicolumn{2}{c}{ Treatment } & \multicolumn{3}{c}{ Subsidy } & \multicolumn{3}{c}{ Subsidy under Tax Credit } \\
\hline Log-level & Level (thousand Euros) & Effect & St.dev. & T-stat & Effect & St.dev. & T-stat \\
\hline 0.000 & 1.000 & 0.001 & 0.003 & 0.403 & -0.003 & 0.005 & -0.527 \\
0.500 & 1.649 & 0.001 & 0.003 & 0.383 & -0.003 & 0.004 & -0.664 \\
1.000 & 2.718 & 0.001 & 0.002 & 0.384 & -0.003 & 0.003 & -0.871 \\
1.500 & 4.482 & 0.001 & 0.002 & 0.410 & -0.003 & 0.002 & -1.109 \\
2.000 & 7.389 & 0.001 & 0.001 & 0.434 & -0.002 & 0.002 & -1.225 \\
2.500 & 12.182 & 0.000 & 0.001 & 0.401 & -0.001 & 0.001 & -1.054 \\
3.000 & 20.086 & 0.000 & 0.001 & 0.199 & -0.001 & 0.001 & -0.783 \\
3.500 & 33.116 & 0.000 & 0.000 & -0.353 & 0.000 & 0.000 & -0.589 \\
4.000 & 54.598 & 0.000 & 0.000 & -0.717 & 0.000 & 0.000 & -0.577 \\
4.500 & 90.017 & 0.000 & 0.000 & -0.835 & -0.001 & 0.001 & -0.891 \\
5.000 & 148.413 & 0.000 & 0.000 & -1.189 & -0.001 & 0.001 & -0.974 \\
5.500 & 244.692 & 0.000 & 0.001 & -0.762 & -0.001 & 0.001 & -0.898 \\
6.000 & 403.429 & 0.000 & 0.001 & -0.345 & -0.001 & 0.001 & -0.627 \\
6.500 & 665.142 & 0.000 & 0.001 & 0.010 & 0.000 & 0.001 & -0.159 \\
7.000 & 1096.633 & 0.000 & 0.001 & 0.461 & 0.000 & 0.001 & -0.044 \\
7.500 & 1808.042 & 0.001 & 0.001 & 0.951 & 0.000 & 0.001 & -0.167 \\
8.000 & 2980.958 & 0.001 & 0.001 & 1.125 & 0.000 & 0.001 & -0.024 \\
8.500 & 4914.769 & 0.002 & 0.002 & 1.152 & 0.000 & 0.001 & 0.056 \\
9.000 & 8103.084 & 0.002 & 0.002 & 1.162 & 0.000 & 0.002 & 0.044 \\
9.500 & 13359.727 & 0.003 & 0.002 & 1.152 & 0.000 & 0.003 & 0.094 \\
10.000 & 22026.465 & 0.004 & 0.003 & 1.128 & 0.001 & 0.004 & 0.143 \\
\hline \hline
\end{tabular}

Note: Treatment effects (Effect) refer to a dose increase of EUR 1,000. Monetary values are deflated at 2000 year price level. 
Table B3: Period 2004 - 2009 - Treatment Effect: Differences in Growth of Private R\&D

\begin{tabular}{cc|ccc|ccc}
\hline \multicolumn{2}{c}{ Treatment } & \multicolumn{3}{c}{ Subsidy } & \multicolumn{3}{c}{ Subsidy under Tax Credit } \\
\hline Log-level & Level (thousand Euros) & Effect & St.dev. & T-stat & Effect & St.dev. & T-stat \\
\hline 0.000 & 1.000 & 0.000 & 0.009 & -0.018 & 0.010 & 0.007 & 1.411 \\
0.500 & 1.649 & -0.001 & 0.008 & -0.085 & 0.008 & 0.006 & 1.383 \\
1.000 & 2.718 & -0.001 & 0.006 & -0.193 & 0.006 & 0.004 & 1.447 \\
1.500 & 4.482 & -0.002 & 0.005 & -0.356 & 0.005 & 0.003 & 1.496 \\
2.000 & 7.389 & -0.002 & 0.004 & -0.594 & 0.003 & 0.002 & 1.174 \\
2.500 & 12.182 & -0.003 & 0.003 & -1.001 & 0.000 & 0.001 & -0.146 \\
3.000 & 20.086 & -0.002 & 0.001 & -1.516 & -0.002 & 0.001 & -1.923 \\
3.500 & 33.116 & -0.001 & 0.001 & -1.339 & 0.000 & 0.001 & -0.495 \\
4.000 & 54.598 & 0.000 & 0.001 & 0.170 & 0.001 & 0.001 & 1.080 \\
4.500 & 90.017 & 0.000 & 0.001 & 0.279 & 0.000 & 0.001 & 0.438 \\
5.000 & 148.413 & -0.001 & 0.001 & -0.802 & -0.001 & 0.001 & -1.821 \\
5.500 & 244.692 & -0.002 & 0.001 & -1.698 & -0.003 & 0.001 & -3.023 \\
6.000 & 403.429 & -0.003 & 0.002 & -1.559 & -0.007 & 0.002 & -3.393 \\
6.500 & 665.142 & -0.003 & 0.002 & -1.615 & -0.008 & 0.002 & -3.605 \\
7.000 & 1096.633 & -0.004 & 0.002 & -1.615 & -0.007 & 0.002 & -3.322 \\
7.500 & 1808.042 & -0.004 & 0.003 & -1.151 & -0.004 & 0.002 & -2.147 \\
8.000 & 2980.958 & -0.003 & 0.004 & -0.752 & -0.002 & 0.003 & -0.836 \\
8.500 & 4914.769 & -0.003 & 0.006 & -0.470 & 0.000 & 0.004 & 0.088 \\
9.000 & 8103.084 & -0.002 & 0.007 & -0.299 & 0.004 & 0.005 & 0.766 \\
9.500 & 13359.727 & -0.002 & 0.009 & -0.200 & 0.008 & 0.006 & 1.261 \\
10.000 & 22026.465 & -0.002 & 0.012 & -0.138 & 0.012 & 0.008 & 1.567 \\
\hline \hline
\end{tabular}

Note: Treatment effects (Effect) refer to a dose increase of EUR 1,000. Monetary values are deflated at 2000 year price level. 